\title{
Tissues of Paralarvae and Juvenile Cephalopods
}

\author{
Raquel Fernández-Gago, Pilar Molist, and Ramón Anadón
}

\begin{abstract}
Cephalopods have a different development to other molluscs and hatch as modified miniature adults called larvae, juveniles or, in some octopuses, paralarvae. The terminology used to describe young cephalopods is varied. In Octopus vulgaris and other members of Octopoda and Teuthida (squids), hatchlings are called paralarvae. They are planktonic stages that swim actively and prey on live planktonic organisms while undergoing morphological changes mainly due to the fast growth of the arms relative to the mantle. Sepia officinalis and other members of the Sepioidea are called hatchlings until they are a week old. All of the specimens studied in this chapter are newly hatched. For a better understanding of the correct terminology, we will refer to the cuttlefish and squid specimens as juveniles and to the $O$. vulgaris specimens as paralarvae. In this chapter, we provide a detailed view of the anatomy of premature hatchlings of the squid (Loligo vulgaris) and the cuttlefish (S. officinalis) and of paralarvae of $O$. vulgaris. We organize this into sections of the functional "systems" (e.g. respiratory system, excretory system).
\end{abstract}

\section{Keywords}

Histology • Anatomy $\bullet$ Squid $・$ Cuttlefish $・$ Octopus $・$ Normal structure

\subsection{Introduction}

Cephalopods have a different development to other molluscs and hatch as modified miniature adults called larvae, juveniles or, in some octopuses, paralarvae (Young and Harman 1988). The terminology used to describe young cephalopods is varied. In Octopus vulgaris, the hatchlings are called paralarvae. They are squid-like, swim actively and prey on live planktonic

R. Fernández-Gago ( $\square)$

Department of Ecology and Animal Biology, University of Vigo,

Lagoas-Marcosende, Vigo, Spain

e-mail: raquelfernandezgago@gmail.com

P. Molist

Department of Functional Biology and Health Sciences,

University of Vigo, Lagoas-Marcosende, Vigo, Spain

e-mail: pmolist@uvigo.es

\section{R. Anadón}

Department of Functional Biology, University of Santiago de Compostela, Campus Vida, Santiago de Compostela, Spain

e-mail: ramon.anadon@usc.es animals while undergoing strong morphological changes mainly due to the fast growth of the arms relative to the mantle (Iglesias et al. 2007). Hanlon and Messenger (1988) named the early Sepia officinalis stages hatchlings until they are a week old. All of the specimens studied in the following chapter are newly hatched. For a better understanding of the correct terminology, we will refer to the cuttlefish and squid specimens as juveniles and to the $O$. vulgaris specimens as paralarvae. In this chapter, a detailed view of the anatomy of premature hatchlings of squid (Loligo vulgaris) and cuttlefish (S. officinalis) and of paralarvae of octopus (O. vulgaris) is presented by "systems" (e.g. respiratory system, excretory system), following a functional approach.

\subsection{Skin and the Body Wall (Fig. 5.1)}

The skin consists of epidermis and dermis. The epidermis of hatchling octopodiformes, $O$. vulgaris, and decapodiformes, L. vulgaris and $S$. officinalis, show differences in morphology. In octopus paralarvae, the epidermis of the head and arms is 

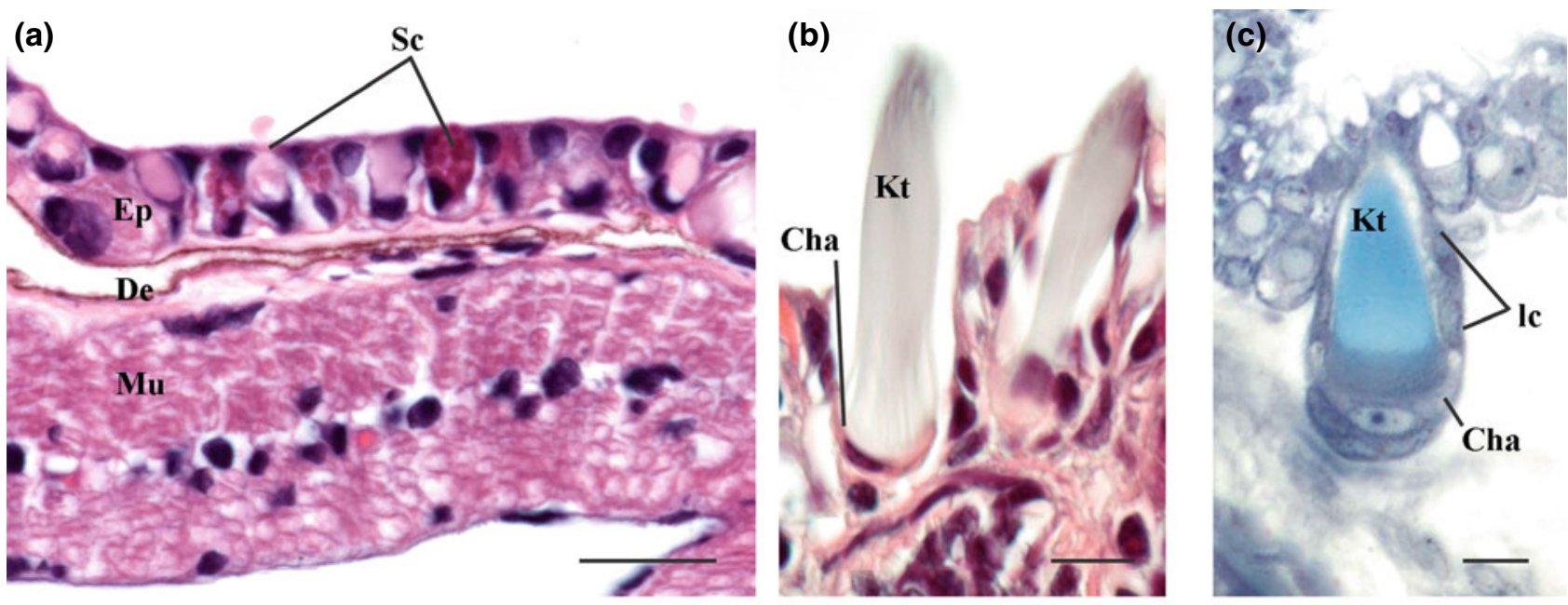

(d)
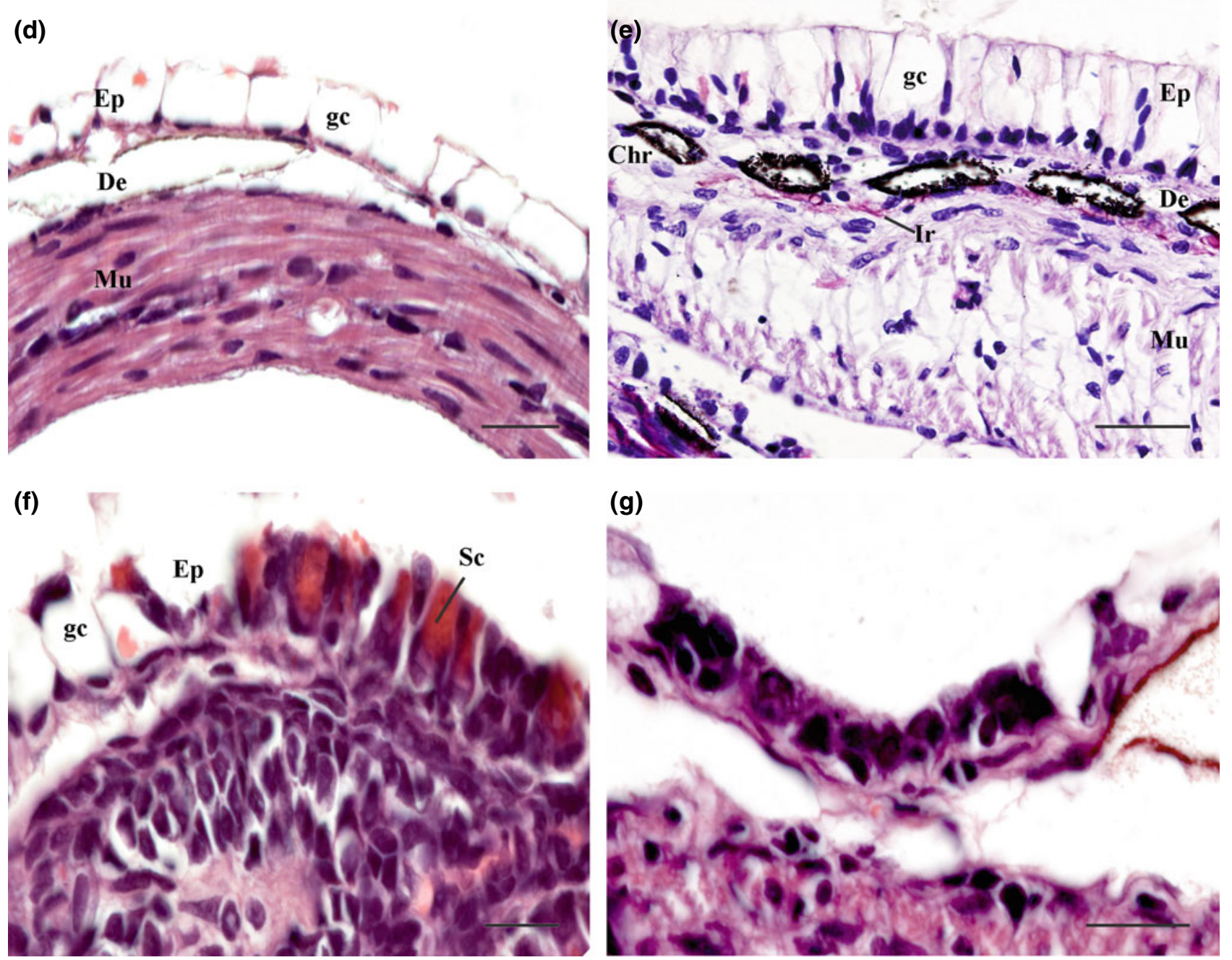

(g)

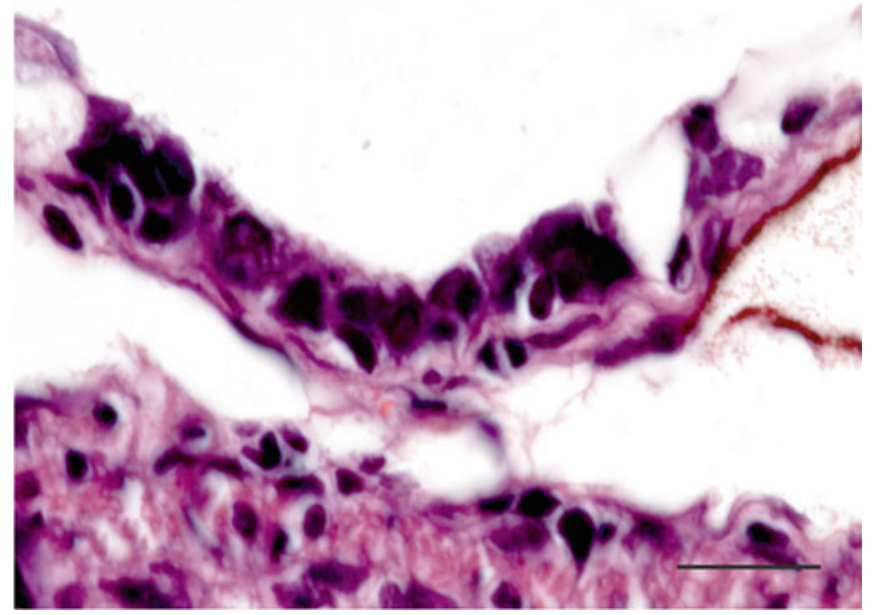

Fig. 5.1 Longitudinal section of the skin of octopus mantle (a). Kölliker organ detail $(\mathbf{b}, \mathbf{c})$. Transversal section of the skin of squid mantle (d). Longitudinal section of the skin of cuttlefish mantle (e). Sections of the skin of squid arm (f). Detail of epidermal line epithelium (g). Cha, chaetoblast; Chr, chromatophoric organs; Ed,

dermis; Ep, epidermis; gc, goblet cell; Kt, Kölliker organ tufts; lc, lateral cell; $\mathrm{Mu}$, musculature; Ir, iridophores (reflecting cells); and Sc, secretory cell. $\mathbf{a}-\mathbf{b}, \mathbf{d}-\mathbf{g} \mathrm{H} \& \mathrm{E}$ stain and $\mathbf{c}$ Richardson blue. Scale bars: a, f, $\mathbf{g} 20 \mu \mathrm{m} ; \mathbf{b}-\mathbf{c} 10 \mu \mathrm{m} ; \mathbf{d} 30 \mu \mathrm{m}$; and e $50 \mu \mathrm{m}$ 
formed by a simple columnar epithelium (Fig. 5.1a). This epithelium is lower than in the mantle. Bi-stratified regions of this epithelium can be seen in some areas. Among the epithelial columnar cells, there are two types of secretory cells (Fig. 5.1a) and a characteristic cell of hatchling cephalopods, the Kölliker organs (Fig. 5.1b, c). Boletzky (1973) and Brocco et al. (1974) electron microscopy studies show that these organs are mainly composed of the epidermis and a dermal muscular layer. The epidermis consists of numerous follicles with specialized epidermal cells (Fig. 5.1c) producing an extracellular fascicle of cannular rodlets (Kölliker's tufts; Fig. 3.1b, c) (Boletzky 1973). The follicle is centred in a specialized basal cell called cystoblast or chaetoblast (Brocco et al. 1974) (Fig. 5.1b, c) that is surrounded by several follicular cells or wall cells (Boletzky 1973) (Fig. 5.1c). The chaetoblast has a large nucleus and apical microvilli that penetrate the base of each rodlet (Brocco et al. 1974). The lateral follicular cells (Fig. 5.1c) are similar to chaetoblasts except for the lack of microvilli. The muscular apparatus consists of a group of striated muscle fibres allowing evagination and spreading of the bundles.

These organs are widely distributed over the surface of paralarvae until 30-35 days post-hatching (Boletzky 1973), although they are more abundant in the mantle than in the head, syphon and arms (Brocco et al. 1974). Kölliker's organs disappear after the first few months of post-embryonic life, so it is assumed they have a function associated with planktonic life. There have been several theories regarding its function: Naef (1923) proposed that these structures help passive planktonic transport in the water column and are a basis for the formation of more complex structures in juveniles and adults, Portmann (1933), Boletzky (1973) and Mangold et al. (1971) hypothesized that these organs help the embryo
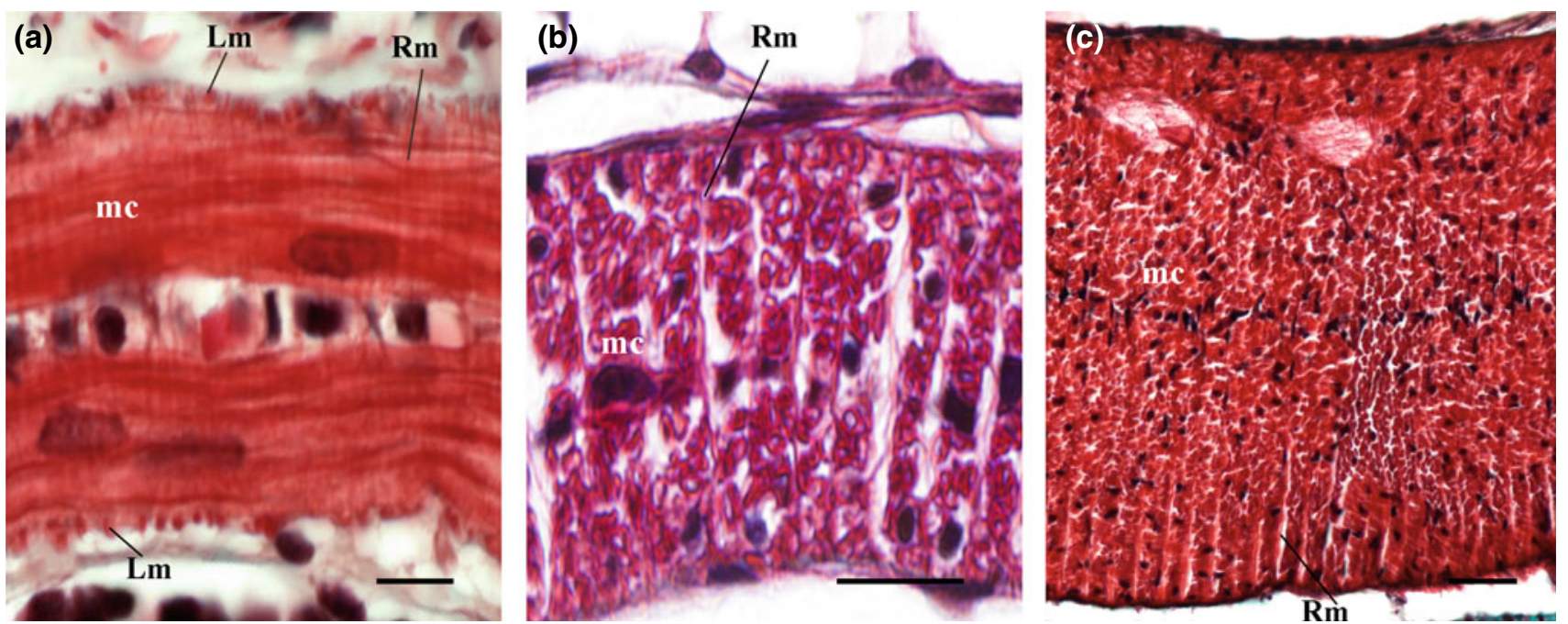

Fig. 5.2 Arrangement of muscle fibres in the muscular layer of the mantle. Transversal sections of octopus (a). Longitudinal sections of squid (b) and horizontal section of cuttlefish (c) mc, circular muscular survival out of the chorion, and Villanueva (1995) suggested that light reflection by tufts of Kölliker's organs could help in the camouflage of the planktonic paralarvae.

In early juvenile squid and cuttlefish, the epidermis (Fig. 5.1d, e) is generally composed of large goblet cells with an ovoid basal nucleus, but in the arms and surrounding eyes, this epithelium is something modified. In the internal region of the arms, the epidermis presents gland cells with eosinophilic secretory granules (Fig. 5.1f). In some regions of the post-embryonic specimens, it is possible to see the lines of epidermal cells that have a rectilinear arrangement (Sundermann 1983). These lines are seen in the arms' external region epithelium and around the eyes. These epidermal lines consist of ciliated and accessory cells (Fig. 5.1g). Accessory cells are slender and elongated with dense cytoplasm and a microvillous apical border. This type of cell has a small and dark nucleus. The ciliated cells are very voluminous and have a central nucleus.

The dermis is a narrow layer below the epidermis, formed by a network of connective tissue with collagen fibres, fibroblasts and various amounts of extracellular matrix. In this layer, there are small chromatophores with the same appearance as in adults. The presence of iridophores, leucophores, photophores and reflecting cells was not observed in octopus and squid hatchling specimens. However, in the cuttlefish dermis, there are abundant chromatophores and iridophores or reflecting cells (Fig. 5.1e).

\subsection{Musculature (Fig. 5.2)}

The muscular mantle wall in octopus consists of three sets of muscular layers orientated in longitudinal, circular and radial directions (Fig. 5.2a). In decapods (Fig. 5.2b, c), the layer; Lm, longitudinal muscular layer; Rm, radial muscular layer and radial muscle fibres. a-c Masson's trichome stain. Scale bars: a $10 \mu \mathrm{m}$; b $20 \mu \mathrm{m}$; and c $50 \mu \mathrm{m}$ 
situation is strikingly different, with two layers in circular and radial orientations (Budelmann et al. 1997). As similarly observed in adults, muscle fibres are arranged in different directions although this arrangement is less significant in hatchling cephalopods. Specifically, the longitudinal and radial musculature is less developed than in adults (Fig. 5.2).

\subsection{Shell (Fig. 5.3)}

The internal cephalopod shells can be classified into chitinous pen or gladius and calcified (cuttlebone).

\subsubsection{Chitinous Pen (L. vulgaris)}

The squid exoskeleton is a chitinous pen constituted mostly of $\beta$-chitin (Hunt and El Sherief 1990; Yun et al. 2013), which is in the dorsal part of the mantle. The loliginid pens are broad and are almost as long as the mantle (Budelmann et al. 1997). The squid pens contain a central axis or rachis, lateral expansions (vane) and the terminal conus. The shell sac in $L$. vulgaris consists of an invaginated monolayer of ectodermal cells with two distinct zones: primary or ventral and secondary or dorsal zones (Hopkins and Boletzky 1994; Fig. 5.3a). The main function of this structure is maintaining rigidity about the longitudinal axis of the animal during swimming.

In larval squid, the shell sac extends along the dorsal midline of the mantle. This sac is a membranous envelope that surrounds the gladius, whose epithelium presents dorsal and ventral differentiation (Fig. 5.3a, b). In the shell sac, the dorsal epithelium is characterized by flat cells with an elongated nucleus, while the ventral epithelium consists of cubic cells with a dark cytoplasm (Fig. 5.3b). The shell sac ultrastructure in hatchling L. vulgaris has been described by Hopkins and Boletzky (1994). These authors identified five kinds of cells: basal cells at the margin in the dorsal and ventral regions low cells of two distinct morphologies in the dorsal zone and tall cells of two distinct morphologies in the ventral zone. In adults, Bizikov (1987) observed three shell layers: the inner layer or hypostracum, the ostracum or medium shell layer and the periostracum or outer shell layer. In larvae, the shell is formed by an eosinophilic homogenous material without any layer.

\subsubsection{Calcified Shell (S. officinalis)}

The sepia cuttlebone is a flat, elongated shell with an oval form (Budelmann et al. 1997). Its dorsal surface is heavily calcified, while the ventral surface has a smooth anterior part and a striped posterior part (siphuncular zone). Each siphuncular stripe is the posterior edge of an interseptal space or shell chamber (Budelmann et al. 1997).

The cuttlebone develops early in embryogenesis (Fioroni 1990). In hatchling cuttlefish, eight to nine complete shell chambers are present (Boletzky 1983). The septa are more spaced than in adults. The lamellar structure provides an indicator of growth because it lays down at fairly regular intervals (Boletzky and Wiedmann 1978).

\subsection{The Digestive System (Figs. 5.4, 5.5, 5.6, $5.7,5.8$ and 5.9)}

The digestive system of larval and paralarval cephalopods is composed of the alimentary canal and digestive glands (anterior and posterior salivary glands, and digestive gland).
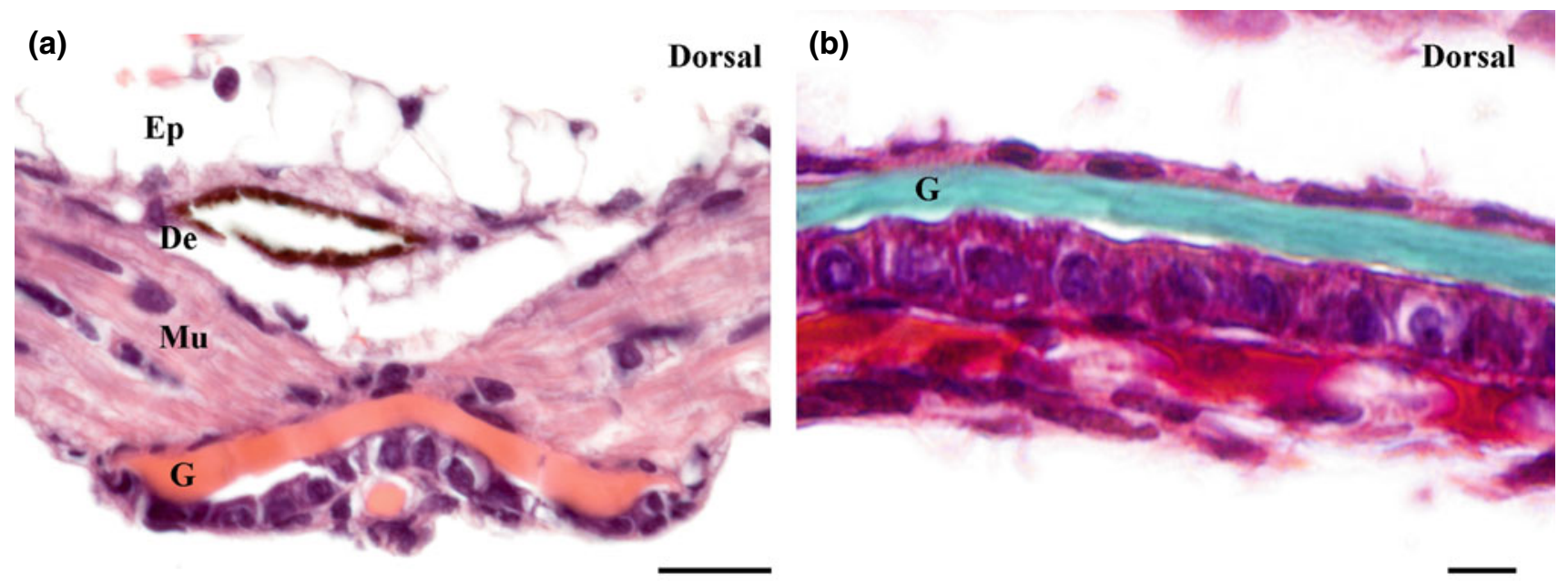

Fig. 5.3 Transversal section of the L. vulgaris pen (a). Longitudinal section of the L. vulgaris pen (b). Ed, dermis; Ep, epidermis; G, gladius; and $\mathrm{Mu}$, muscular layer. a-b H\&E stain. Scale bars: a $20 \mu \mathrm{m}$ and b $10 \mu \mathrm{m}$ 

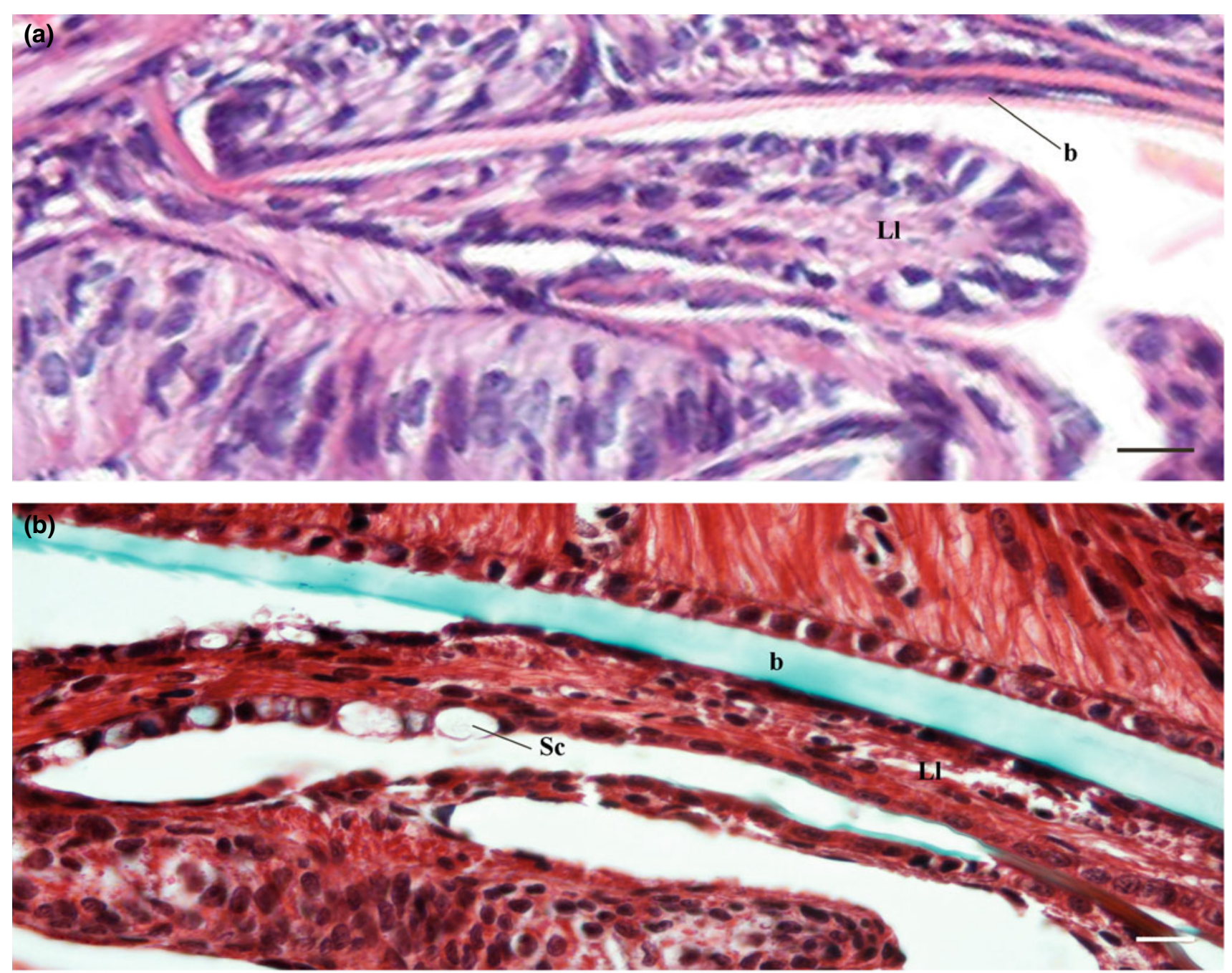

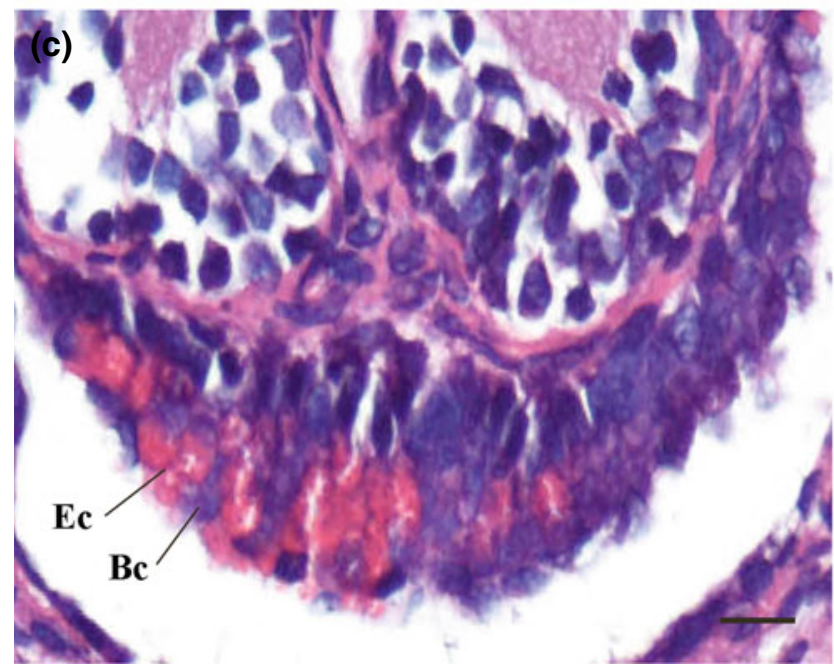

Fig. 5.4 Longitudinal section of $O$. vulgaris lateral lobe (a). Horizontal section of $S$. officinalis lateral lobe (b). Detail of $O$. vulgaris submandibular gland (c). Detail of L. vulgaris submandibular gland (d). B, beak; Bc,

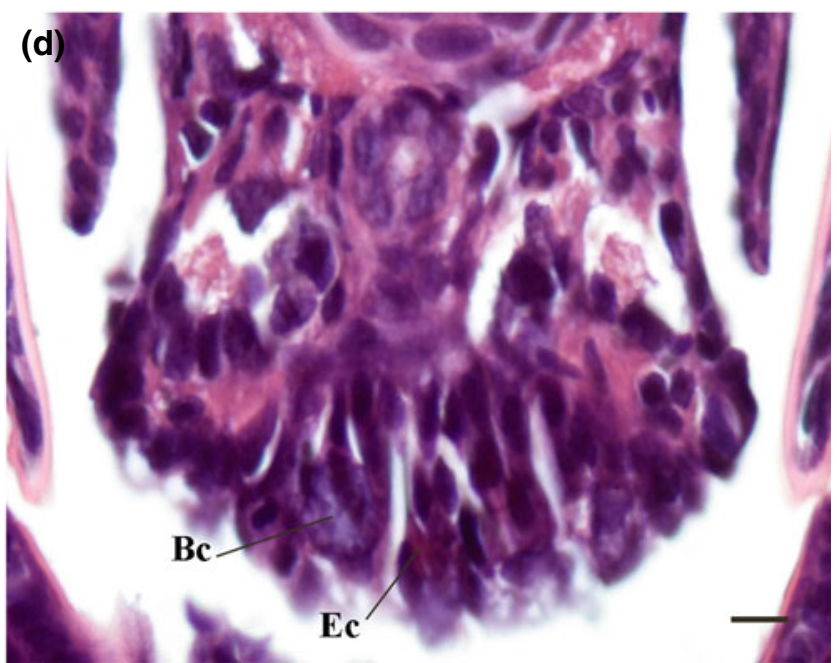

basophilic cell; Ec, eosinophilic cell; Ll, lateral lobe; and Sc, secretory cell. a, c, d H\&E stain and b Masson's trichome stain. Scale bars: a, c $10 \mu \mathrm{m}$ and $\mathbf{b}, \mathbf{d} 20 \mu \mathrm{m}$ 

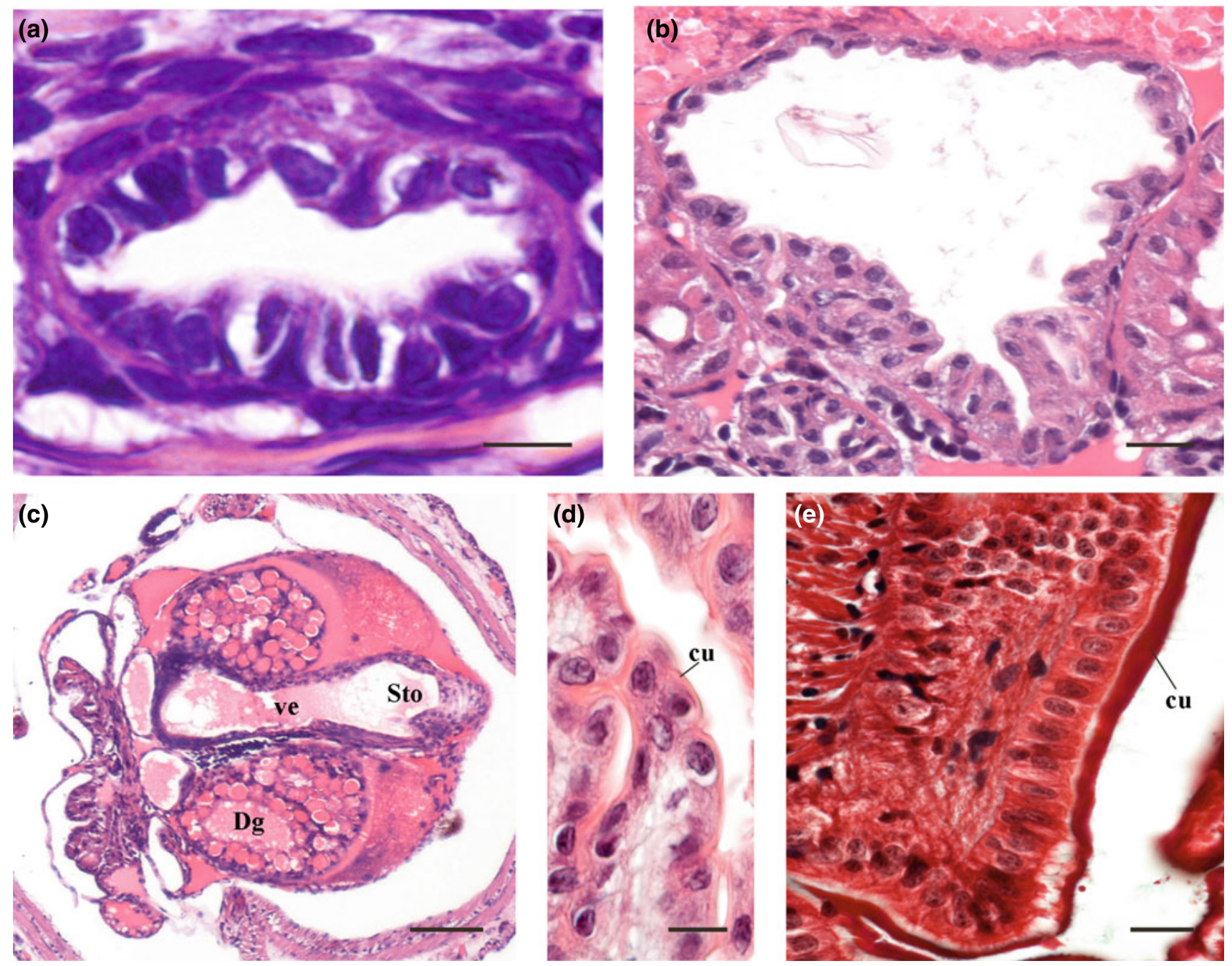

Fig. 5.5 Transversal section of $L$. vulgaris oesophagus (a). Transversal section of $O$. vulgaris crop (b). Transversal section of $O$. vulgaris stomach and vestibule (c). Detail of $O$. vulgaris stomach epithelium (d). Detail of $S$. officinalis stomach epithelium (e). Cu, cuticle; Dg, digestive

gland; eW, external wall; Sto, stomach; and ve, vestibule. a-d H\&E stain and e Masson's trichome stain. Scale bars: a, d $10 \mu \mathrm{m}$; b $20 \mu \mathrm{m}$; and $\mathbf{c} 100 \mu \mathrm{m}$

Different regions are distinguishable in the canal: buccal mass, oesophagus, stomach, caecum and intestine. Functionally, the digestive system is a complex system that plays an important role in the absorption of essential nutrients (Fernández-Gago et al. 2017).

The digestive system of octopus paralarvae and of squid and cuttlefish larvae is a U-shaped tube, as in the adults and juveniles of the species. The descending U-branch is in dorsal position and consists of the buccal bulb and oesophagus. A crop is also found in octopus (Fernández-Gago et al. 2017). The stomach and the caecum are located in the curve of the U-shaped tube. The ascending U-branch, which is ventral, is formed by the intestine and the anus.
Between the ascending and the descending branches of the $\mathrm{U}$, the digestive gland and the posterior salivary glands are visible. All regions of the digestive system are already formed one day post-hatching. Although the histology of the digestive tube varies along its length, the following layers can be observed from inside out: the mucosa, the submucosa, the muscular layer and the serosa.

Similarly to adults, the buccal mass is formed by different structures that contribute to the feeding process, namely: mandibles, radula, salivary papilla, submandibular gland and the secretory ducts of the posterior and anterior salivary glands. The overall anatomy of the different parts of the buccal bulb is very similar to adults, although with some histological 

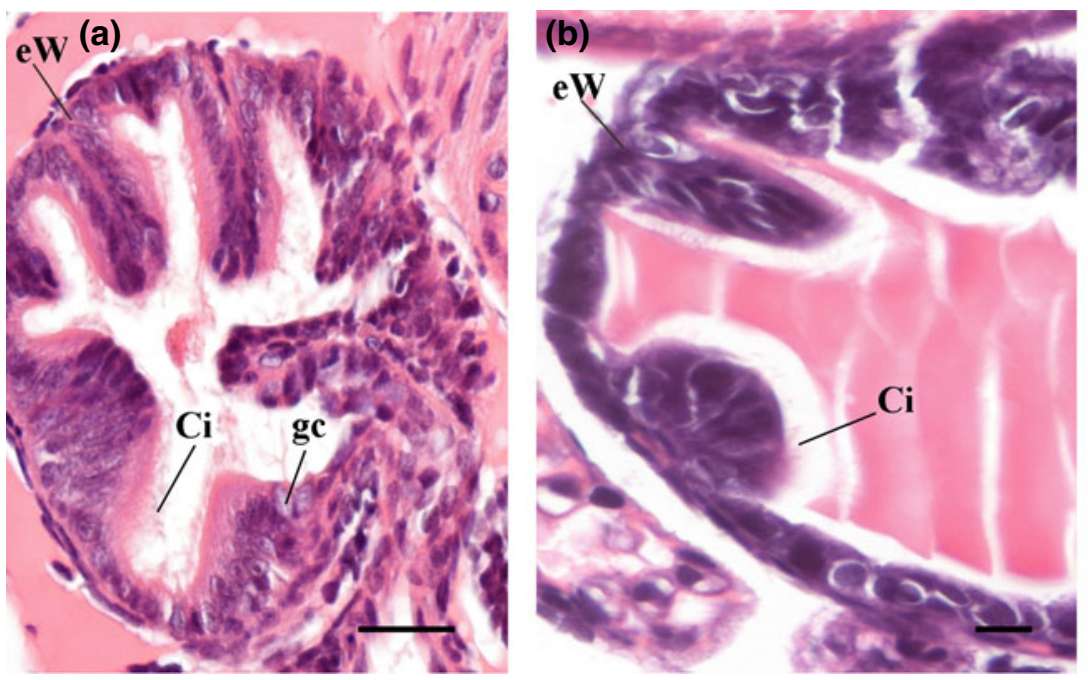

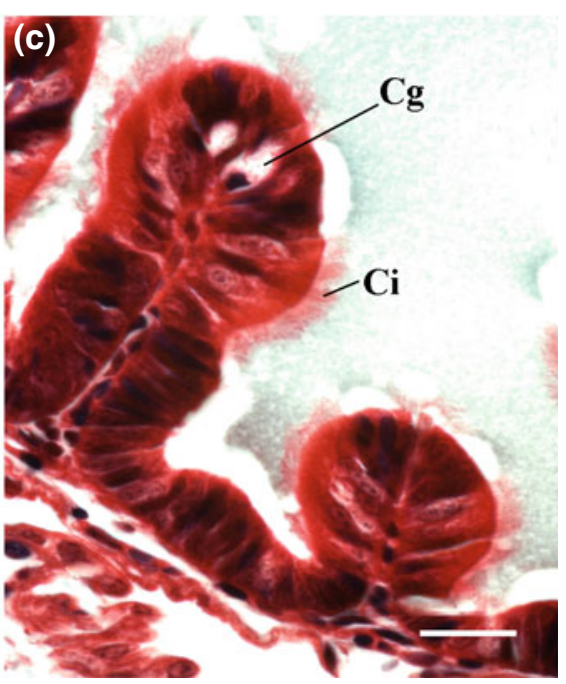

Fig. 5.6 Transversal sections of O. vulgaris caecum (a). Detail of $L$. vulgaris caecum epithelium (b). Detail of $S$. officinalis caecum epithelium (c). $\mathrm{Cg}$, caecal gland; $\mathrm{Ci}$, cilia; eW, external wall; and gc, goblet cell. a-b H\&E stain and $\mathbf{c}$ Masson's trichome stain. Scale bars: a, c $25 \mu \mathrm{m}$ and b $10 \mu \mathrm{m}$ differences. The buccal lateral lobes, which form the food passage, are underdeveloped in larvae and paralarvae.

The food passage is lined by a simple cubic epithelium with cubical cells instead of the typical prismatic cells of adults (Fig. 5.4a, b). The glandular epithelia associated with the posterior part of the lateral lobes and jaws are absent at these stages. The submandibular gland consists of a simple glandular epithelium formed by two types of secretory cells: granular and mucous. In octopus paralarvae, the zonal arrangement of these two types of cell is characteristic. The granular cells are located in the middle of the epithelium, while mucous cells are in the lateral regions of the gland (Fig. 5.4c). However, in squid, both types of cell appear mixed (Fig. 5.4d).

The oesophagus is a muscular tube formed by a mucosa with folds or villi of different sizes. Unlike in adults, it is lined by a low simple epithelium with a thin cuticle. Moreover, in the hatchling squid, the oesophagus does not have folds in its mucosa (Fig. 5.5a). The crop of octopus paralarvae is a tubular structure with a distended lumen. In the crop, the mucosa forms small villi or longitudinal folds that differ from the adult in the fact that they are not branched (Fig. 5.5b).

In hatchling cephalopods, the stomach is a sac-like organ with a simple folded mucosal epithelium (Fig. 5.5c). In octopus and squid, the stomach epithelium is formed by cubic cells with a large and central nucleus (Fig. 5.5d), but in cuttlefish, the stomach epithelium is formed by cylindrical cells (Fig. 5.5e). The three species have the apical region of the cells covered by a thin non-stratified cuticle.

The caecum of cuttlefish and octopus hatchlings, as in adults, shows a histological differentiation between the external and internal walls. The external wall contains only primary folds of the mucosa that consist of a pseudostratified epithelium, whereas in the internal wall the unfolded mucosa is formed by a simple epithelium (Fig. 5.6a). The caecum of juvenile squid presents the differentiated regions of the ciliated organ and the caecal sac. The ciliated organ has the same differentiation between the internal and external walls (Fig. 5.6b), but these are missing in the caecal sac (Bidder 1950). No secretory cells have been found in the ciliated organ of the squid, unlike in the adults. The only gland cells present in the caecum of paralarvae are located at the entrance or exit of this organ to the vestibule (Fig. 5.6a), lacking secretory cells in the internal and external walls, as well as the caecal glands typical of adults. However, in hatchling cuttlefish, the caecum has secretory cells and the caecal glands in the apical region of the folds (Fig. 5.6c).

The octopus and squid intestines are a tubular organ that presents structural differences at the level of the mucosa. In the ventral region of the mucosa, there are two broad longitudinal folds that resemble the adult typhlosoles (Fig. 5.7a, b), but they are comparatively less developed. These folds present a thick ciliated pseudostratified epithelium 

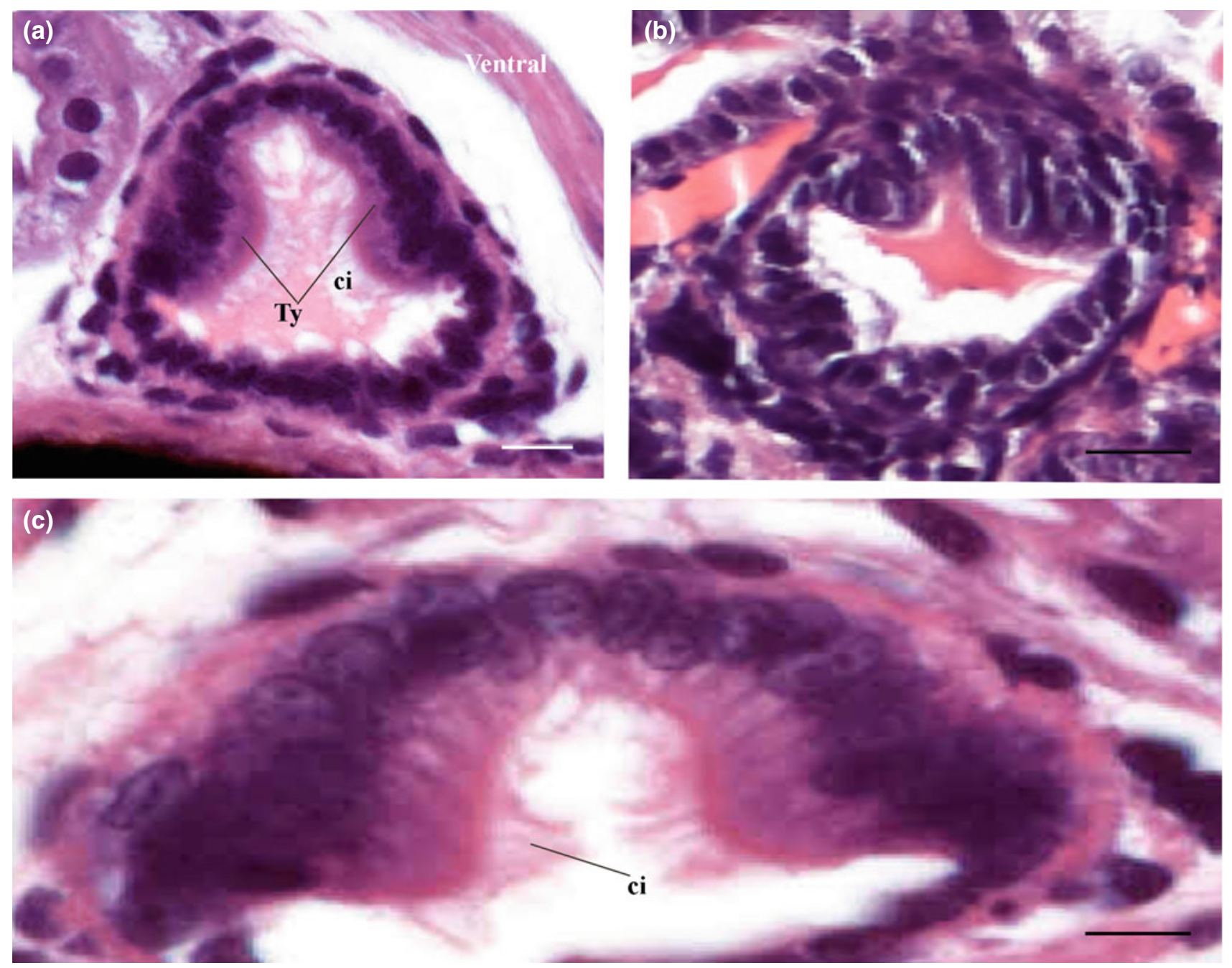

Fig. 5.7 Transversal section of the intestine of Octopus vulgaris paralarvae (a). Transversal section of the intestine of squid (b). Detail of the typhlosole epithelium (c). ci, cilia and Ty, typhlosole. a-c H\&E stain. Scale bars: a $10 \mu \mathrm{m} ; \mathbf{b} 20 \mu \mathrm{m}$; and c $5 \mu \mathrm{m}$

(Fig. 5.7c). The two folds are only present in the region of the intestine close to the vestibule, whereas, in the remainder tube, there are no folds or villi in the mucosa, which consists of a simple squamous epithelium. In the dorsal region, a thickening of this wall was observed (Fig. 5.7a, b). No secretory cells are present in the intestinal mucosa.

\subsubsection{Annex Glands}

Unlike the adults, the anterior salivary glands of the squid and octopus hatchlings are simple and have no ramifications (Fig. 5.8a, b). These glands show, in octopus, two types of glandular cells with granular secretion, eosinophils and basophils as well as a type of gland cell with mucous secretion. The epithelium lining this gland shows a greater proportion of eosinophilic gland cells than the other two types (Fig. 5.8b). Due to the absence of secretory cells, the anterior salivary gland in squid does not yet have a secretory function, which may be due to its premature state (Fig. 5.8a).

The posterior salivary glands (Fig. $5.8 \mathrm{c}, \mathrm{d}$ ) of the hatchlings have a morphological structure similar to those in adults. The secretory units of these glands show two types of gland cells: (i) cells with granular eosinophilic secretion and (ii) cells with mucous basophilic secretion. However, in the case of $O$. vulgaris paralarvae the yellow granular cells, typical in adults, are not present.

The single digestive gland of newly hatched octopus paralarvae has tubules with a simpler structure than those in 

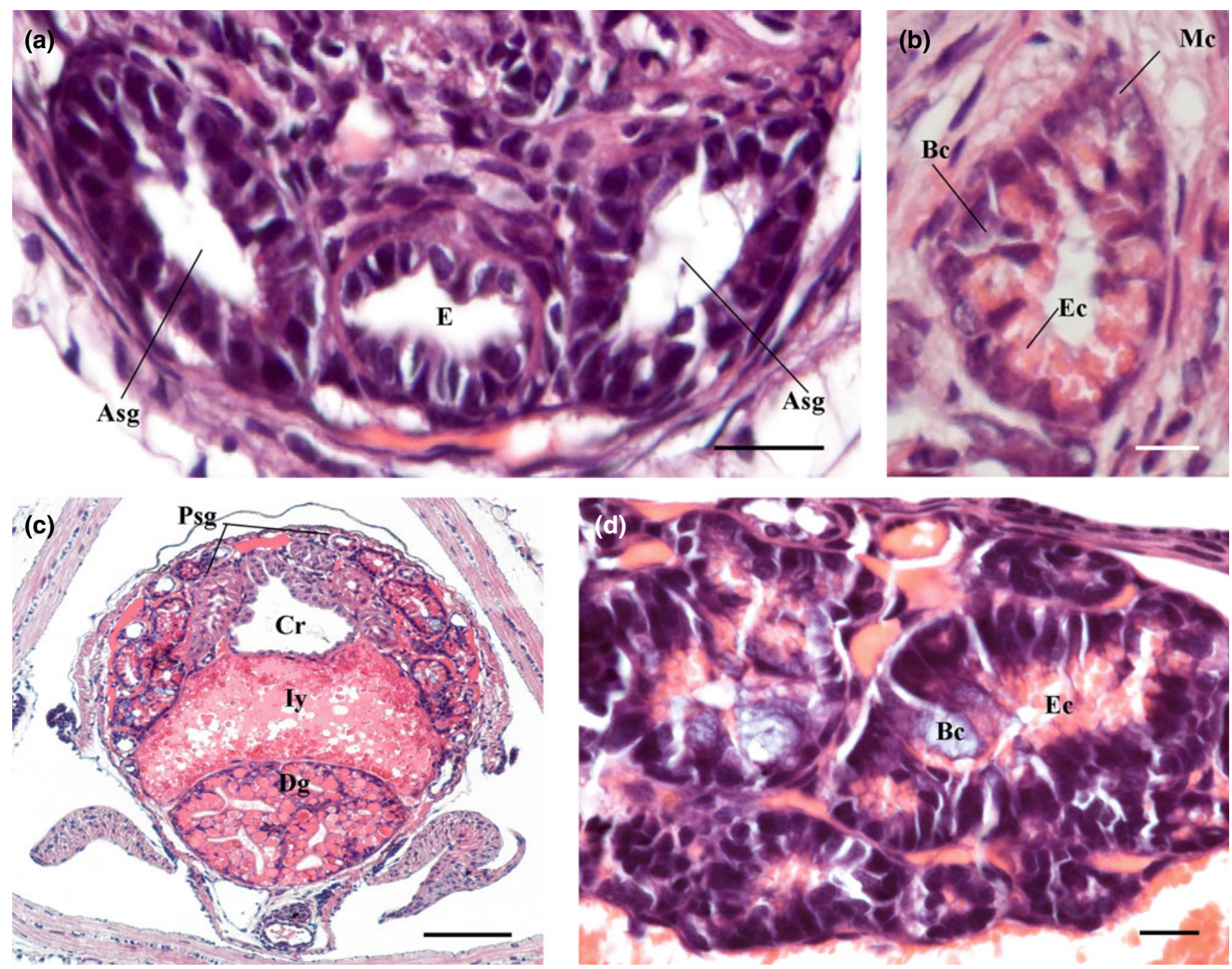

Fig. 5.8 Transversal section of the anterior salivary glands of a squid larva (a). Detail of the anterior salivary gland of an octopus paralarva (b). Transversal section of octopus showing the posterior salivary glands (c). Detail of the posterior salivary gland of a squid larva (d). Asg, anterior

salivary gland; Bc, basophilic cell; Cr, crop; Dg, digestive gland; E, oesophagus; Ec, eosinophilic cell; Iy, internal yolk; and Psg, posterior salivary gland. a-d H\&E stain. Scale bars: a $50 \mu \mathrm{m}$; b $10 \mu \mathrm{m}$; c $100 \mu \mathrm{m}$; and $\mathbf{d} 20 \mu \mathrm{m}$

adults (Fig. 5.9a). These tubules are characterized as having a lumen and a poorly defined cellular organization, showing only a basement membrane and two types of cell: immature digestive cells and storage cells (Fig. 5.9b). The latter cells show an appearance similar to mature digestive cells of adults, but its cytoplasm appears expanded due to abundant yolk plaques and inclusions of different sizes. Lemaire et al. (1977) described storage cells and cells that have boules in the basal region and a microvilli border in the apical region. In squid, the two digestive glands appear at both sides of the internal yolk. They are tubular and lack yolk plaques
(Fig. 5.9c). However, this absence seems indicate that they are premature hatchlings (early juvenile) than a distinctive feature of this stage of development. The digestive gland of cuttlefish has a similar structure to that in octopus (Fig. 5.9d). The internal yolk of squids and octopuses is composed of a cluster of yolk platelets of different sizes (Fig. 5.9a, c) with the sizes decreasing from the centre to the periphery. This internal yolk is separated from the digestive gland by a thin membrane. While the paralarvae internal yolk is formed by a single elongated mass running parallel to the digestive gland, the juvenile squid internal yolk consists 

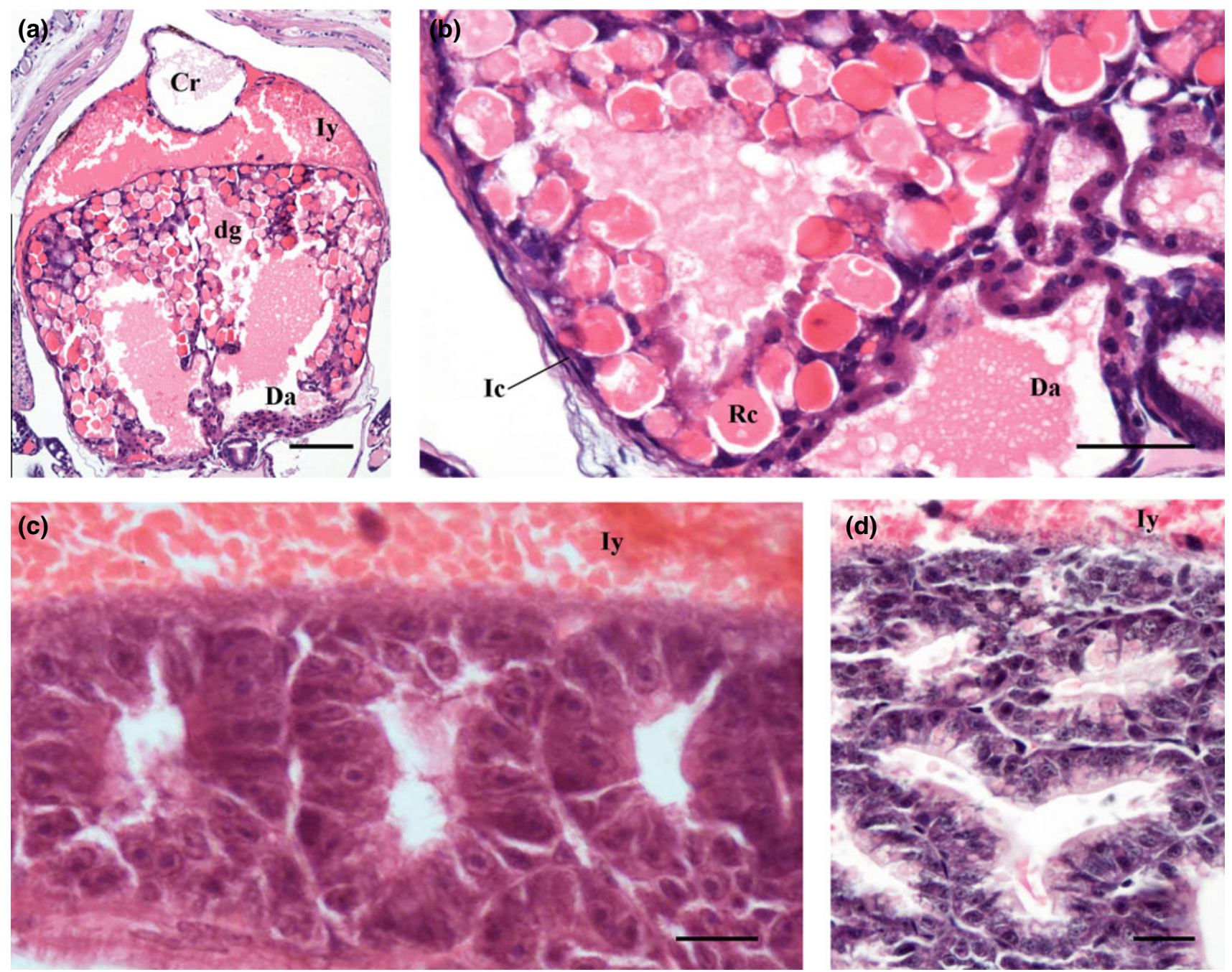

Fig. 5.9 Transversal section of the digestive gland of paralarval octopus (a). Detail of octopus main digestive gland and digestive gland appendages (b). Longitudinal section of $L$. vulgaris digestive gland (c). Longitudinal section of the digestive gland of larval cuttlefish (d). Cr, crop; Da, digestive appendages; dg, digestive gland; lc, basal cell or immature cell; ly, internal yolk; and Rc, reserve cell. a-d H\&E stain. Scale bars: a $100 \mu \mathrm{m}$; b $50 \mu \mathrm{m}$; c $20 \mu \mathrm{m}$; and d $25 \mu \mathrm{m}$ of anterior and posterior masses located at the back of the mantle.

\subsection{Circulatory System (Fig. 5.10)}

\subsubsection{Branchial Glands}

In adults, the branchial glands are a dense paired structure. These glands extend the whole length of the gills. The branchial gland is contained in a capsule consisting of a columnar cell epithelium (Dilly and Messenger 1972). It presents a uniform appearance with numerous acini groups of cells. These acini are formed by some characteristic basophilic cells with a large nucleus near the base of the cell. In hatchling cephalopods, the branchial glands are present (Fig. 5.10a). Similarly to adults, these are dense structures formed by basophilic cells with a central round large nucleus (Fig. 5.10b). However, the well-developed cord structure present in adults is not seen in hatchlings. These glands have a similar structure in squid and octopus.

\subsubsection{White Body (Hematopoietic Organ)}

The hematopoietic organ or white body is a multilobular gland behind the eyeball in cephalopod adults. In octopods 

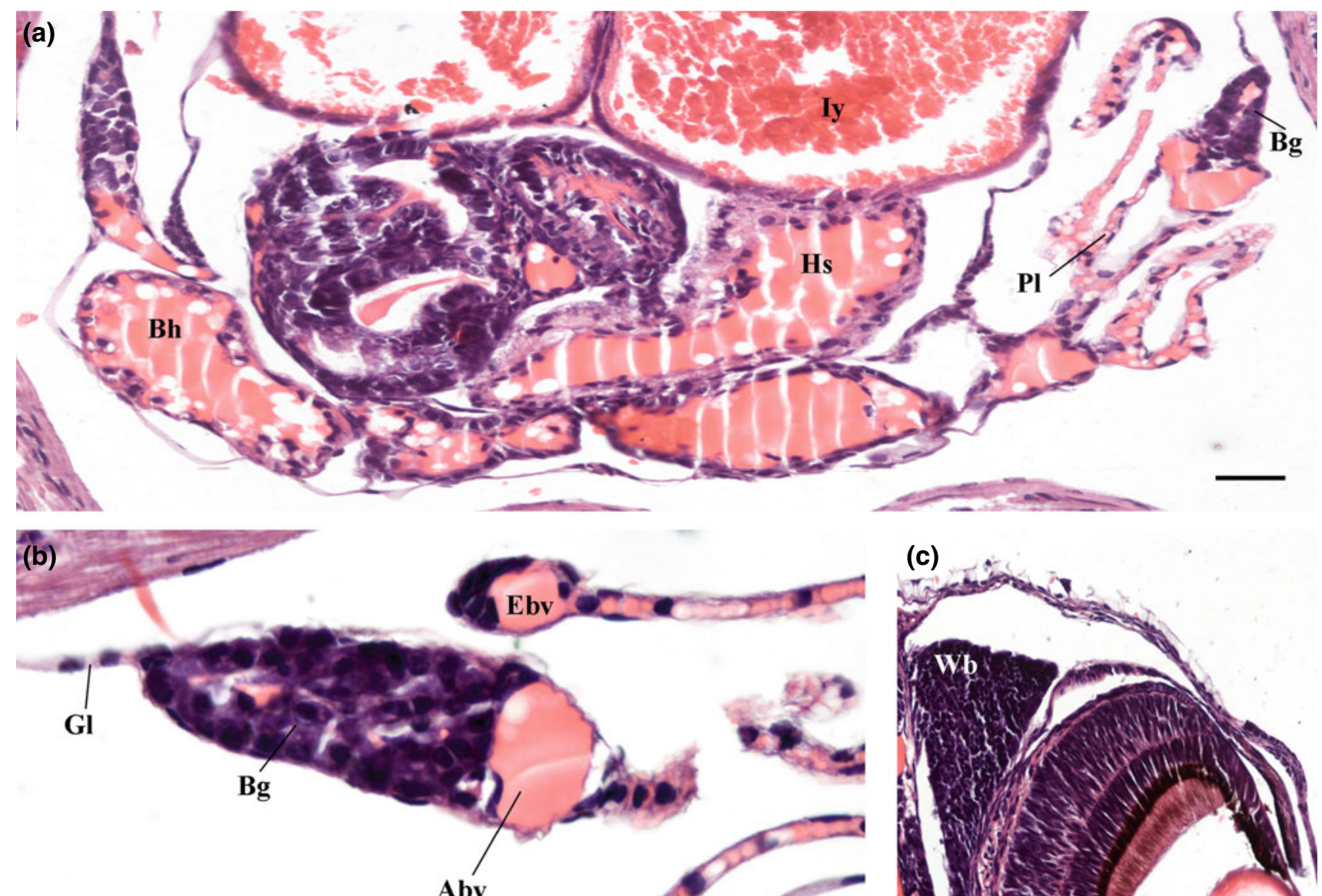

(c)
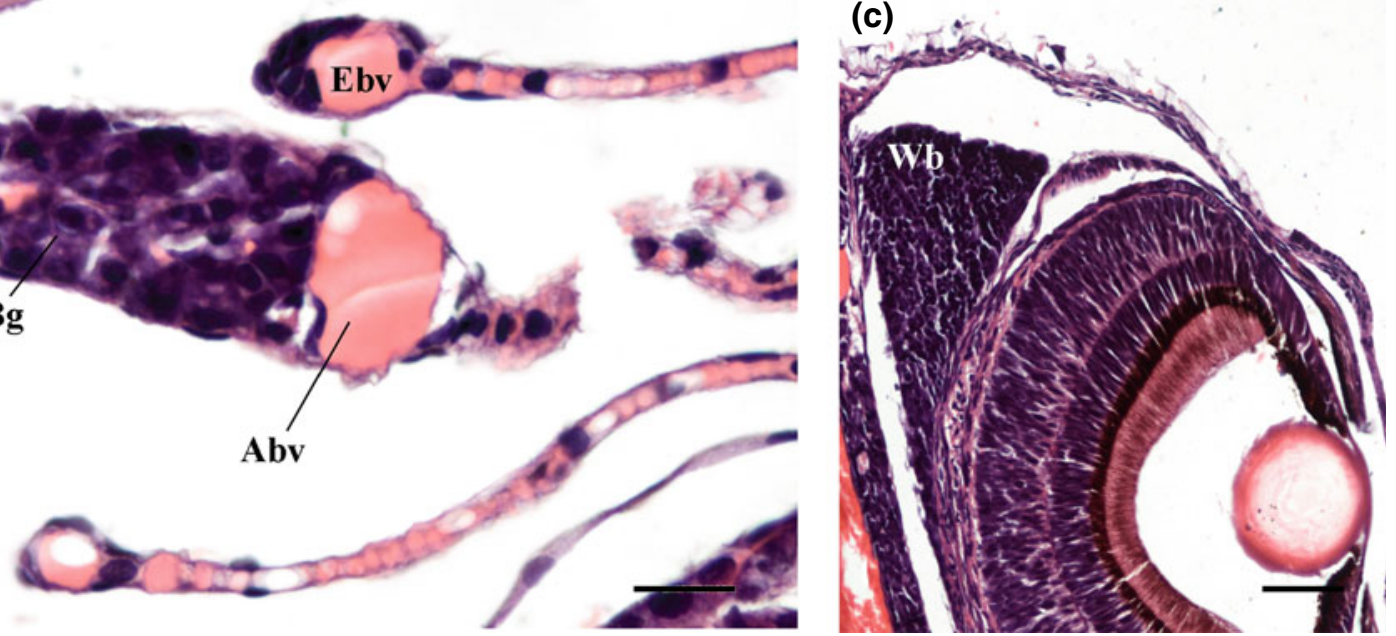

Fig. 5.10 Transversal section of $L$. vulgaris circulatory and respiratory systems (a). Detail of $L$. vulgaris branchial gland (b). Transversal section of the L. vulgaris head showing the eye and the associated white body (c). Abv, afferent blood vessel; Bg, branchial gland; Bh,

branchial heart; Ebv, efferent blood vessel; Gl, gill ligament; Hs, systemic heart; Iy, internal yolk; Pl, primary lamella; and $\mathrm{Wb}$, white body. a-c H\&E stain. Scale bars: a-c $50 \mu \mathrm{m}$ and b $100 \mu \mathrm{m}$

and decapods, this gland is well vascularized and has relatively few collagen fibres (Johnson 1987). Similarly to adults, the white body of the hatchling cephalopods is located between the eye and the optic lobe and is made up of a tight group of small blood cells (Fig. 5.10c).

\subsubsection{Systemic and Branchial Hearts}

The cephalopods have a completely closed circulatory system which is well developed with an extended artery and vein net. The system is like the circulatory system of vertebrates (Schipp 1987). Among the Cephalopoda, the Coleoidea have two auricles, branchial hearts, and a single ventricle, systemic heart. The vessel system is formed of arteries and veins which are linked by a capillary network and a peripheral sinus and lacunae where a gas exchange occurs.

The systemic heart is a powerful muscle with a lumen which is divided by a muscular heart septum into two equally large chambers (Kling and Schipp 1987). The main moving force of blood circulation is produced by the heart and is supported by other contractile organs (Kling and Schipp 1987). Therefore, the function of this is to be the central motor of the high-pressure circulatory system. The branchial hearts are deep red to yellow-brown colour with a much branched narrow lumen (Schipp and Schäfer 1969). 
This organ also has other different functions: to assist filtration for the formation of primary urine, to store important substances, to aid in the excretion of catabolites and in the immune defence mechanism (Fielder and Schipp 1987).

The wall of the ventricle and the auricles has three main layers: epicardium, myocardium and endocardium. The epicardium is formed by flat extended epithelial cells with microvilli. The myocardium has a different structure in the systemic and branchial hearts (Budelmann et al. 1997). It is a spongy layer containing muscle fibres and polygonal cells rich in the cytoplasm and containing an ovoid nucleus. This layer is more developed in the systemic heart and is composed of many muscle layers. However, in the branchial heart, this layer is only formed by one or two layers of densely innervated muscle fibres (Budelmann et al. 1997). As it is observed in adults, the myocardium is formed by cardiomyocytes similar to the vertebrate cardiomyocytes (Schipp and Schäfer 1969). The third layer is an incomplete endothelium towards the lumen, but sometimes it is not developed at all (Fielder and Schipp 1987). This layer is formed by a continuous basal lamina with flattened endothelial cells and myocytes (Kling and Schipp 1987; Budelmann et al. 1997).

The post-hatching cephalopod ventricles and auricles have a large lumen. These organs have poorly developed walls. Paralarvae and juveniles have a strong musculature in the systemic heart similar to adults. The branchial heart in hatchling cephalopods has a large lumen, unlike in adults. In the organ wall, it is possible to see the typical cells of this organ with a dense black vacuole (Fig. 5.10a).

\subsection{The Respiratory System (Figs. $\mathbf{5 . 1 0}$ and 5.11)}

The dibranchiate cephalopods (coleoids) have a pair of gills protruding from an expandable mantle cavity where the flow of respiratory water passes through their folds. This water flow is produced by the powerful contractions of a highly elastic mantle muscle system (Budelmann et al. 1997). A pair of branchial hearts generate part of the circulatory pressure and pump the blood via the afferent branchial vessel (branchial artery) that lies in the gill ligament, to the gill lamellae where it is oxygenated. It is passed to the systematic heart by active pulsations of the efferent branchial vein (Schipp et al. 1979). The cephalopod gills serve for respiratory and excretory functions (Schipp et al. 1979).

The gills are composed by lamellae, which are organized symmetrically in Sepia and asymmetrically in octopods
(Budelmann et al. 1997). In O. vulgaris, each gill has a central cavity, with the primary lamellae on each side. The primary lamella is folded along its long axis so that a series of secondary lamellae are formed, alternating on the two sides of the primary ones (Wells and Wells 1982). The secondary lamellae are branched and form tertiary lamellae. The main afferent vessel runs along the dorsal margin of the gill and down the inner surface of each primary lamella. From here, it branches along the crest of the secondary lamella. Cuttlefish gills are less complex. These are divided into a series of compartments by membranous partitions. One such runs vertically along the length of the gill, dividing it into two. The afferent vessel from the branchial heart runs along the groove formed at the bottom of the gill. The corresponding efferent vessel is external (Thompsett 1939). The secondary and tertiary lamellae are crossed by the arteries and veins of the second and third orders. Between the veins and arteries of the third order, the blood runs in "lacunae". This is the region of gas exchange (Schipp et al. 1979; Wells and Wells 1982).

In the hatchlings of octopus and squid, the gills are scarcely branched, in contrast to the deeply branched gills of the cuttlefish (Fig. 5.11). Paralarvae and juveniles only have a primary lamella (Fig. 5.11a), which in its distal portion ends in a bulbous protrusion, where a blood sinus is found (Fig. 5.10b). Similarly to adults, it is possible to observe the gill gland as well as the afferent vessels from the branchial heart (Fig. 5.10b). The epithelium of the lamellae varies from cubic to squamous in different gill areas of octopus, while this epithelium is squamous in squid (Fig. 5.11a, c). In juvenile cuttlefish, the gill shows differences in height and inner structure of the concave and convex epithelial surfaces of secondary folds (Fig. 5.11b). The height of the epithelium of the concave side is nearly twice that of the outer side epithelium and appears more vacuolated (Schipp et al. 1979). The inner epithelium (concave side) is formed by tall cells exhibiting some vesicles and a large vacuole (Fig. 5.11d). The outer (convex) epithelium is a simple squamous epithelium with a well-developed microvillous apical border (Budelmann et al. 1997).

\subsection{The Excretory System (Fig. 5.12)}

In cephalopod excretion, the organs involved are the renal complex, with the renal and digestive appendages, and the branchial heart complex, with their appendages or pericardial glands and the brachial heart (Furuya et al. 2004). The digestive gland and the white body also collaborate in this function (Boucher-Rodoni and Mangold 1988). 

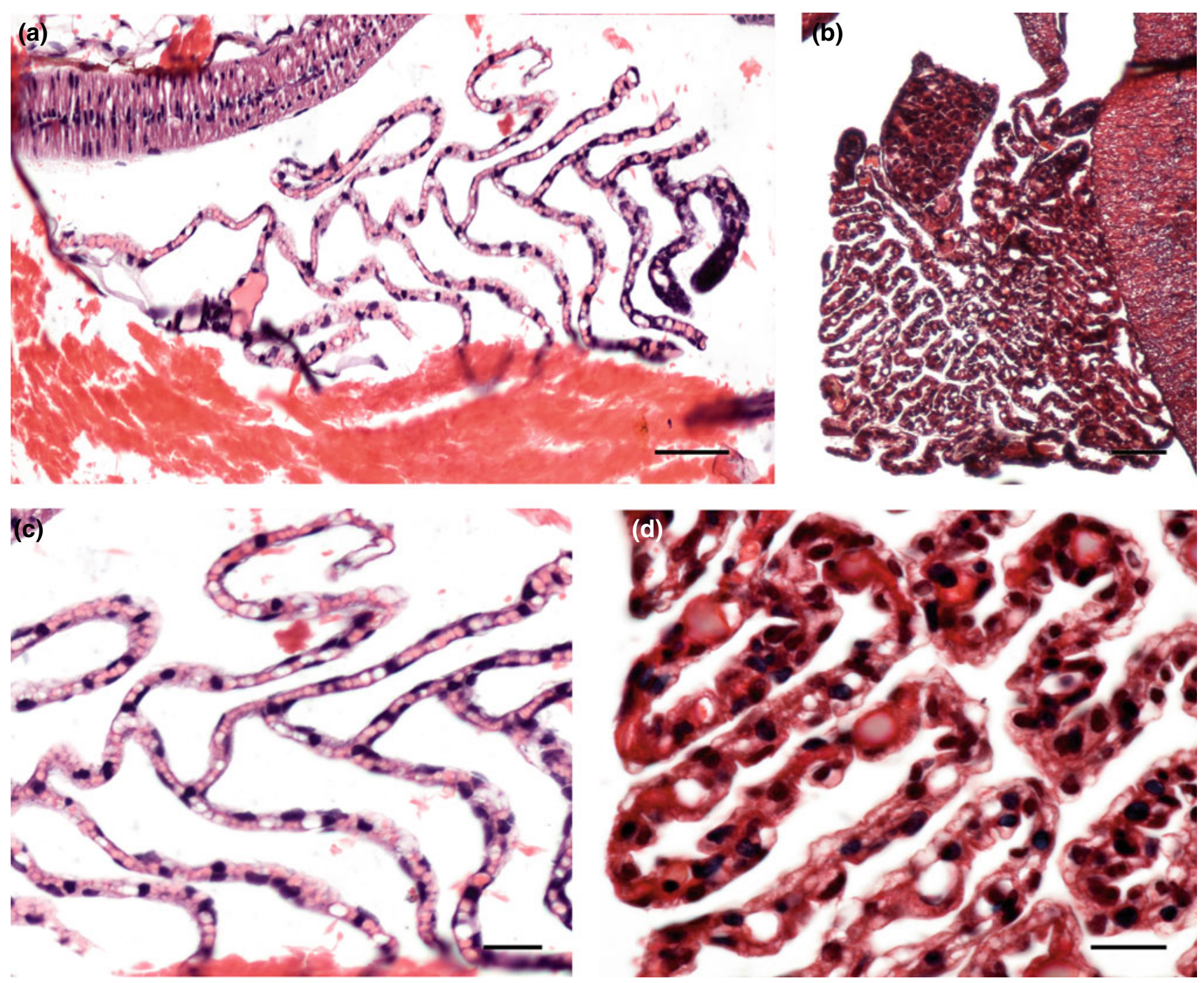

Fig. 5.11 Longitudinal section of the Loligo vulgaris gill (a). Horizontal section of $S$. officinalis gill (b). Detail of the L. vulgaris gill epithelium (c). Detail of the S. officinalis gill epithelium (d).

a, $\mathbf{c} H \& E$ stain and $\mathbf{b}, \mathbf{d}$ Masson's trichrome stain. Scale bars: a $50 \mu \mathrm{m}$; b $100 \mu \mathrm{m}$; and $\mathbf{c}-\mathbf{d} 25 \mu \mathrm{m}$

\subsubsection{Renal Appendages}

In adult octopods, the renal appendages are protrusions in the coelom cavity with grooves and folds that cover the vena cava and its branches. These appendages consist of a single-layered columnar epithelium with apical microvilli. The renal appendages of decapods have the same structure that has been observed in octopus, with deep grooves and folds (Furuya et al. 2004) coated by a columnar epithelium with microvilli. However, these cells are characterized as the presence of numerous mitochondria in the apical region and in the area of the basal labyrinth, as well as by many large

dense lysosomes with high acid phosphatase activity (Budelmann et al. 1997). Below the epithelium lies a blood "lacuna" with an incomplete layer of endothelial cells (only a few fibroblasts and collagenous fibres), but also an extensive network of fine oblique striated muscle cells is observed. This network of muscle fibres is responsible for the rhythmic contractions of the renal appendages, which support the flow of the haemolymph and urine (Budelmann et al. 1997).

Furuya et al. (2004) established that the renal appendages differ between juveniles and adults of different species, the latter always exhibiting a more complex surface of renal appendages than in juveniles. In octopus paralarvae, the 


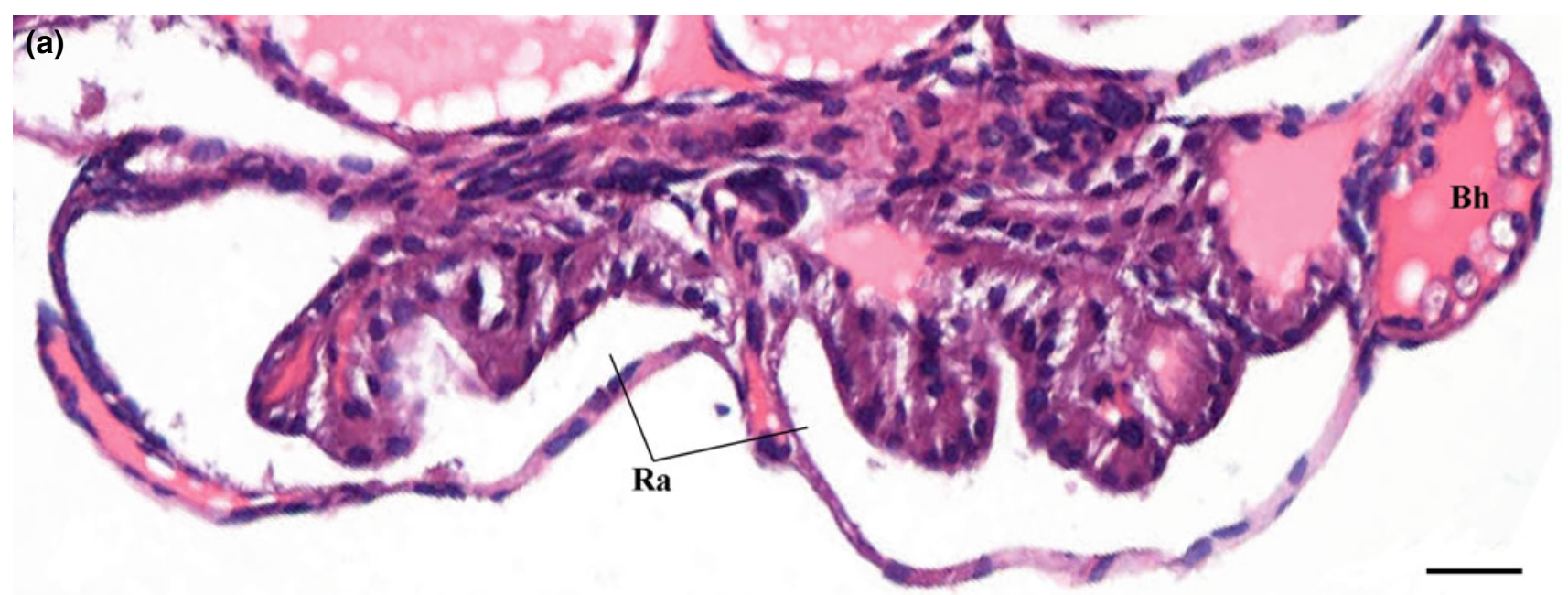

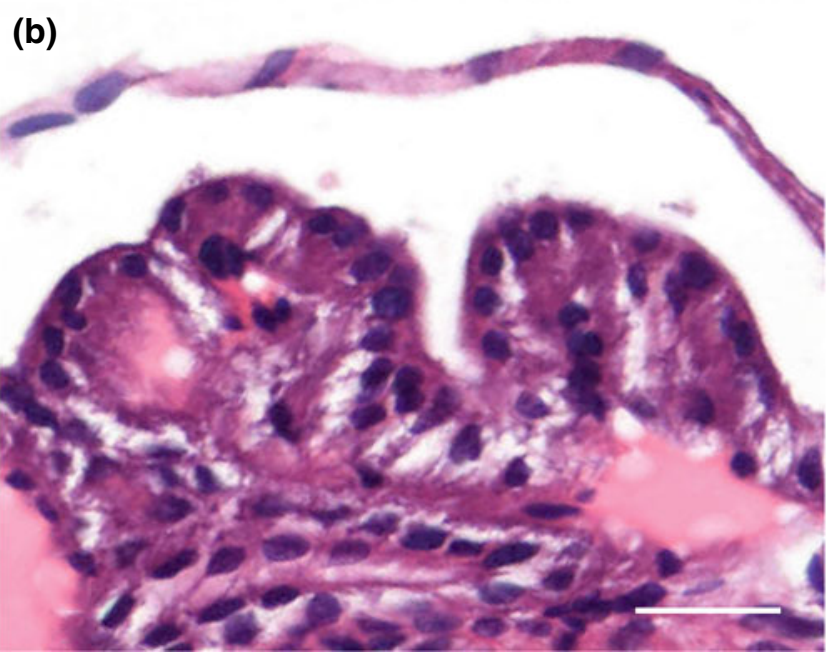

Fig. 5.12 Transversal section of renal appendages of an $O$. vulgaris paralarva protruding in the renal coelom (a). Detail of the epithelium of renal appendages (b). L. vulgaris digestive appendages, transversal

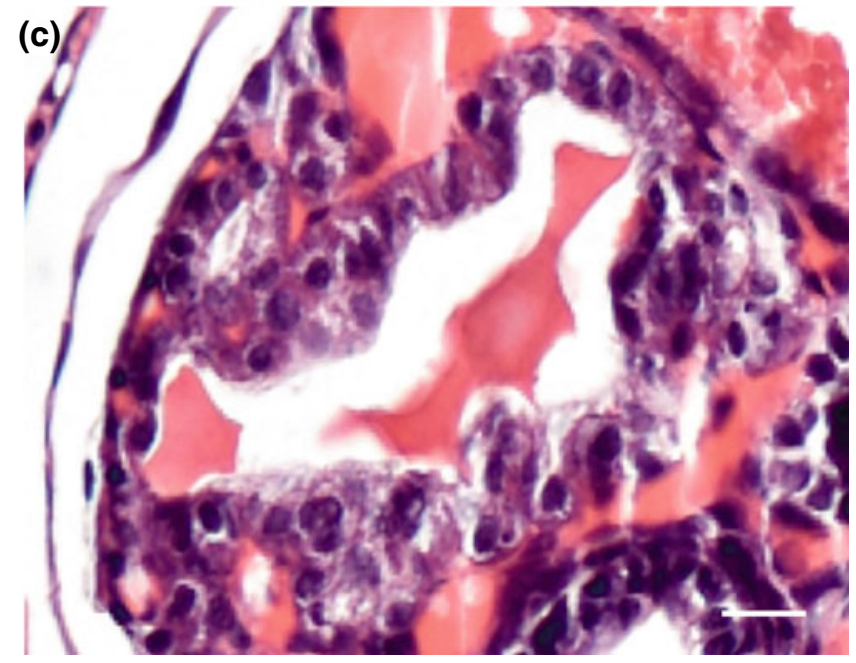

view (c). Bh, branchial heart and $\mathrm{Ra}$, renal appendages. H\&E stain. Scale bars: $\mathbf{a}-\mathbf{b} 25 \mu \mathrm{m}$ and $\mathbf{c} 10 \mu \mathrm{m}$

inner pancreatic epithelium) lie in parallel, separated by a capillary system and a small amount of connective tissue (Budelmann et al. 1997). The juvenile pancreatic appendages are less folded and show a simple cubic epithelium (Fig. 5.12c).

\subsubsection{Branchial Heart Appendages or Pericardial Glands}

The cephalopod pericardial gland is a structure connected with the branchial heart that projects into the coelom. In cuttlefish, these appendages are conical and have grooves and folds. Apparently, these structures are not developed in post-hatching stages (Derby 2014). 

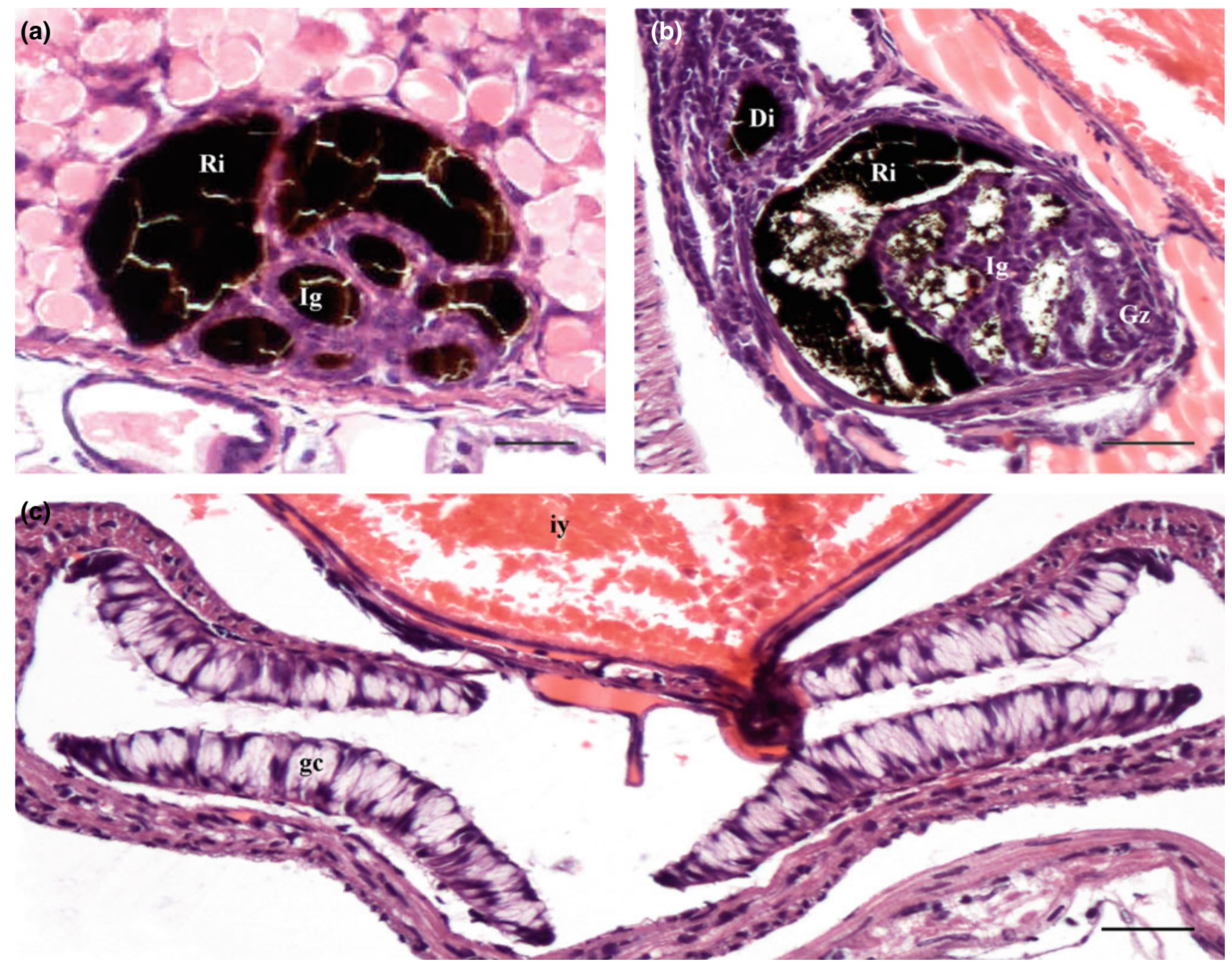

Fig. 5.13 Transversal section of $O$. vulgaris showing the ink sac (a). Longitudinal section of the L. vulgaris ink sac (b). L. vulgaris funnel organ, transversal view (c). Gc, goblet cell; Gz, basal germinal zone;
Di, ink sac duct; Ig, ink gland; iy, internal yolk; and Ri, ink sac or reservoir. a-c H\&E stain. Scale bars: a $25 \mu \mathrm{m}$ and b-c $50 \mu \mathrm{m}$

\subsubsection{Ink Gland Complex (Fig. 5.13)}

The Coleoidea species have ink sacs and produce ink, but some coleoids have lost their ink sac. For example, this is true in the case of the octopod species in the Cirrata suborder (Budelmann et al. 1997). The ink gland complex consists of three parts: the ink gland, the ink reservoir and the ink sac duct (Budelmann et al. 1997). The ink is produced by the secretions of two glands, the ink gland (in the ink sac) and the funnel gland (Derby 2014). The combined secretion of these two glands, produced in different quantities, leads to ink different forms (Derby 2014).

\subsubsection{Ink Sac}

This gland is exocrine and produces the ink. The epithelium of the gland complex inner wall is formed by a columnar glandular epithelium, whereas the outer wall is formed by iridophores (Mangold et al. 1989). The ink gland is divided by lamellae that are composed of muscle and collagenous fibres. The gland centre has a tubuloalveolar structure with a cubical epithelium (Budelmann et al. 1997). In hatchling cephalopods, it is possible to see the ink gland complex and its structures (gland sac and duct). The gland presents a cubic epithelium, while the ink sac wall is formed by a squamous epithelium (Fig. 5.13a, b). 


\subsubsection{Funnel Organ}

The funnel organ is the second gland contributing to the ink secretion (Derby 2014). This is a mucous gland on the funnel inner surface (Budelmann et al. 1997). In adult squids, this gland is formed by columnar goblet cells with a dark cytoplasm and a nucleus in the basal region (Laurie 1888). This organ has morphological differences between different species. This organ is usually $\mathrm{W}$-shaped in octopuses, but in Sepioidea it consists of a dorsal inverted V-shaped and paired lateral pads (Voss 1963).
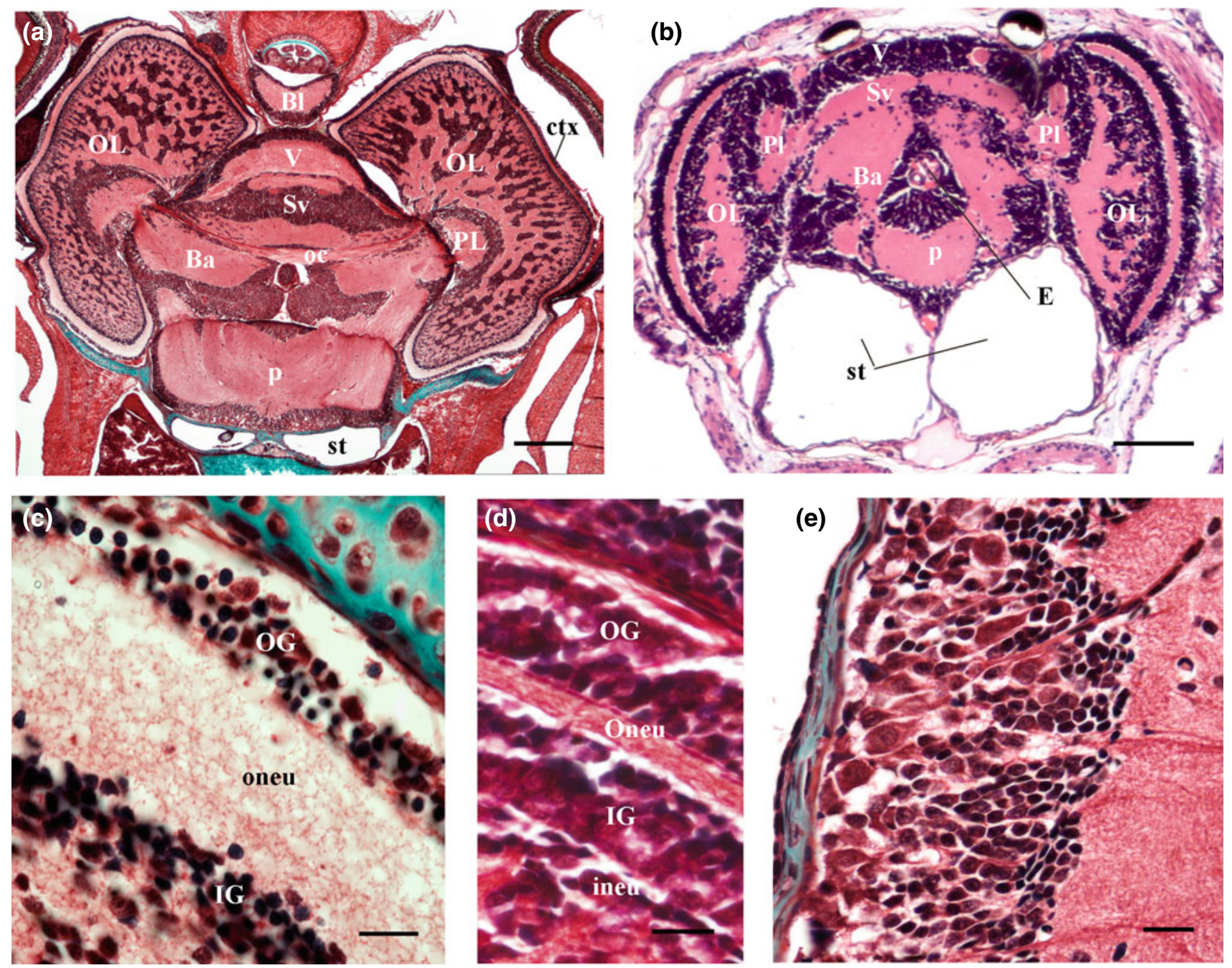

Fig. 5.14 Horizontal section of the $S$. officinalis brain at the level of the optic commissure (a). Horizontal section of the $O$. vulgaris brain (b). Detail of $S$. officinalis optic lobes (c). Detail of $L$. vulgaris optic lobes (d). Detail of the outer layer of the S. officinalis pedal lobe (e). $\mathrm{Ba}$, basal lobe; ctx, cortical laminas; E, oesophagus; IG, inner granular;
This organ is present in hatchling squid, cuttlefish and octopus. In juvenile squids (Fig. 5.13c), this organ has the same morphology as observed by Voss (1963) for Sepioidea. This gland has a glandular epithelium composed of columnar goblet cells with clear cytoplasm and a basal nucleus.

\subsection{Central Nervous System or Brain} (Fig. 5.14)

Cephalopods have the most complex brain of all invertebrates (Young 1977, 1979). The central nervous system can 
morphologically be divided into sub- and supra-oesophageal areas, partitioned by the oesophagus. On each side of the peri-oesophageal lobes are the large optic lobes which comprise an outer cortex and a central medulla. The brain areas are divided into many lobes (Young 1977, 1979); in the Coleoidea, brain has been characterized by twenty-five major lobes (Young 1971). The central mass lobes have a pattern of central neuropil (nerve fibres) and a surrounding cortex (cell bodies). The brain lobe proportions change between hatchling, juveniles and adult stages of life (Frösch 1971). These changes have been correlated with morphological developments and changes in behaviour and habitat (Messenger 1973; Nixon and Mangold 1996; Shigeno et al. 2001). The modes of brain development vary between species (Yamazaki et al. 2002). The tactile memory centres grow faster than the swimming centres in benthic species. However, the optic lobes increase with growth in pelagic species (Yamazaki et al. 2002). Basically, the eyes and nervous system of a variety of hatchling cephalopod species follow the same pattern; they vary interspecifically in size, proportion and complexity (Wild et al. 2015).

The optic lobes of hatchling squid, cuttlefish and octopus are similar in relative size and tissue organization to those of adults (Fig. 5.14a, b). The outer cortex is formed by three layers: two of them contain small neurons that are densely packed (outer and inner granular layers), and in the middle, there is a layer of optic nerve fibres (outer neuropil or plexiform layer) (Fig. 5.14c). Below the inner granular
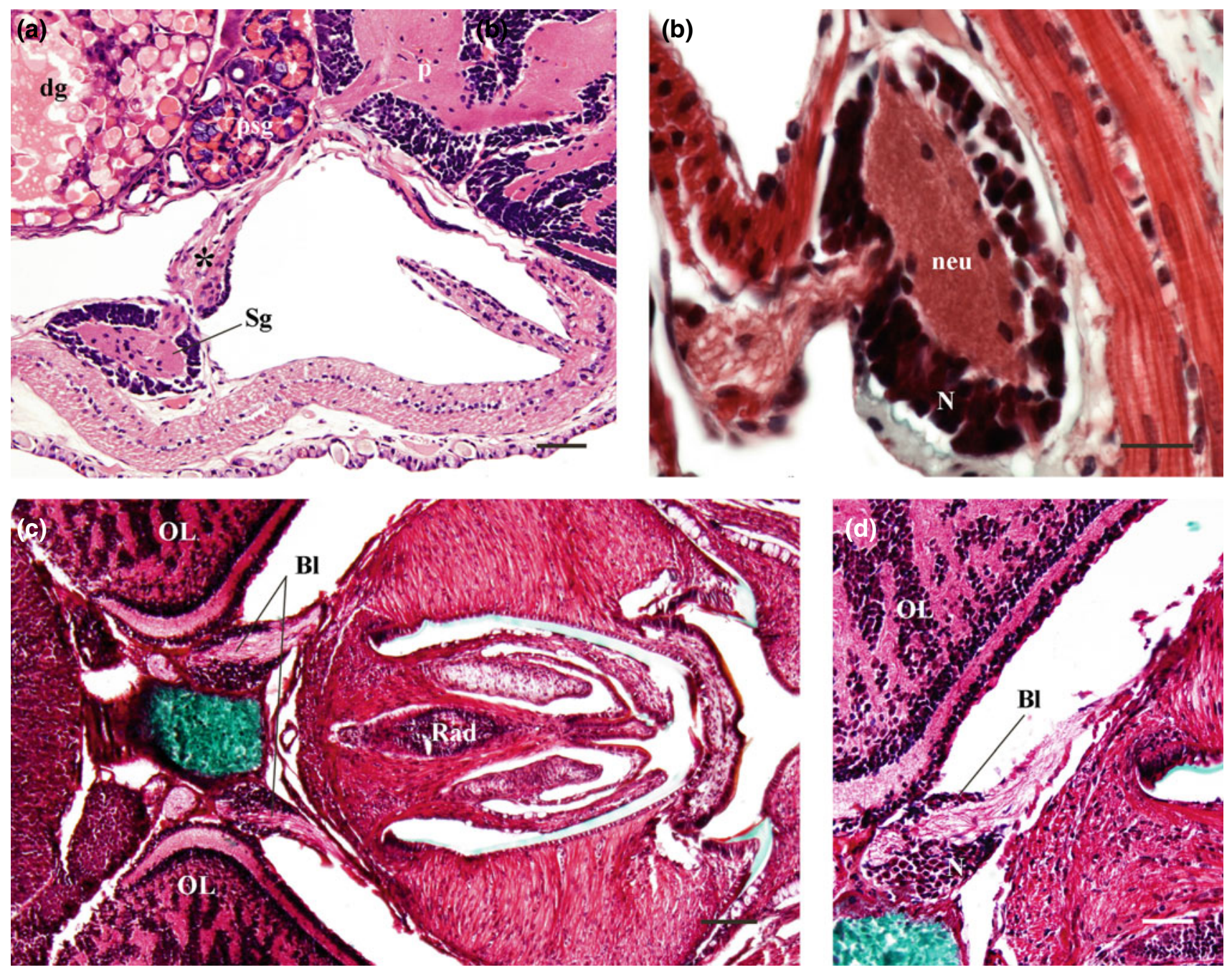

Fig. 5.15 Horizontal section of $O$. vulgaris connection (*) between the pedal lobe and stellate ganglion (a). Detail of $O$. vulgaris stellate ganglion (b). Horizontal section of $S$. officinalis buccal ganglion (c). Detail of $S$. officinalis buccal ganglion (d). Bl, buccal lobe; dg, digestive gland; $\mathrm{N}$, neurons; neu, neuropil; OL, optic lobes; $\mathrm{p}$, pedal lobes; psg, posterior salivary gland; Rad, radula sac; and $\mathrm{Sg}$, stellate ganglion. a H\&E stain and b-d Masson's trichrome stain. Scale bars: a, c $100 \mu \mathrm{m} ; \mathbf{b} 20 \mu \mathrm{m}$; and d $50 \mu \mathrm{m}$ 
layer, the neurons are arranged in columns separated by neuropil which are more abundant in the medulla (Fig. 5.14a, b). However, in the hatchlings of $L$. vulgaris a thin second plexiform layer (inner) is seen just below the inner granular layer (Fig. 5.14d) (Wild et al. 2015). From each optical lobe, an optic tract crosses the brain forming the optic commissure (Fig. 5.14a). The optic commissure is well developed and can be divided into dorsal (Fig. 5.14a) and ventral optic commissures (Wild et al. 2015). The peduncle commissure lies tightly adjacent to the dorsal optic commissure (Wild et al. 2015).

The cerebral ganglia in hatchling cephalopods are less developed, lacking the complex organization observed in the adults. Nevertheless, the general architecture of the brain formed by suboesophageal and supra-oesophageal lobes has been observed (Fig. 5.14a, b). Moreover, ganglia which are connected with the cerebral ganglia via connectives and commissures are also observed along the body.
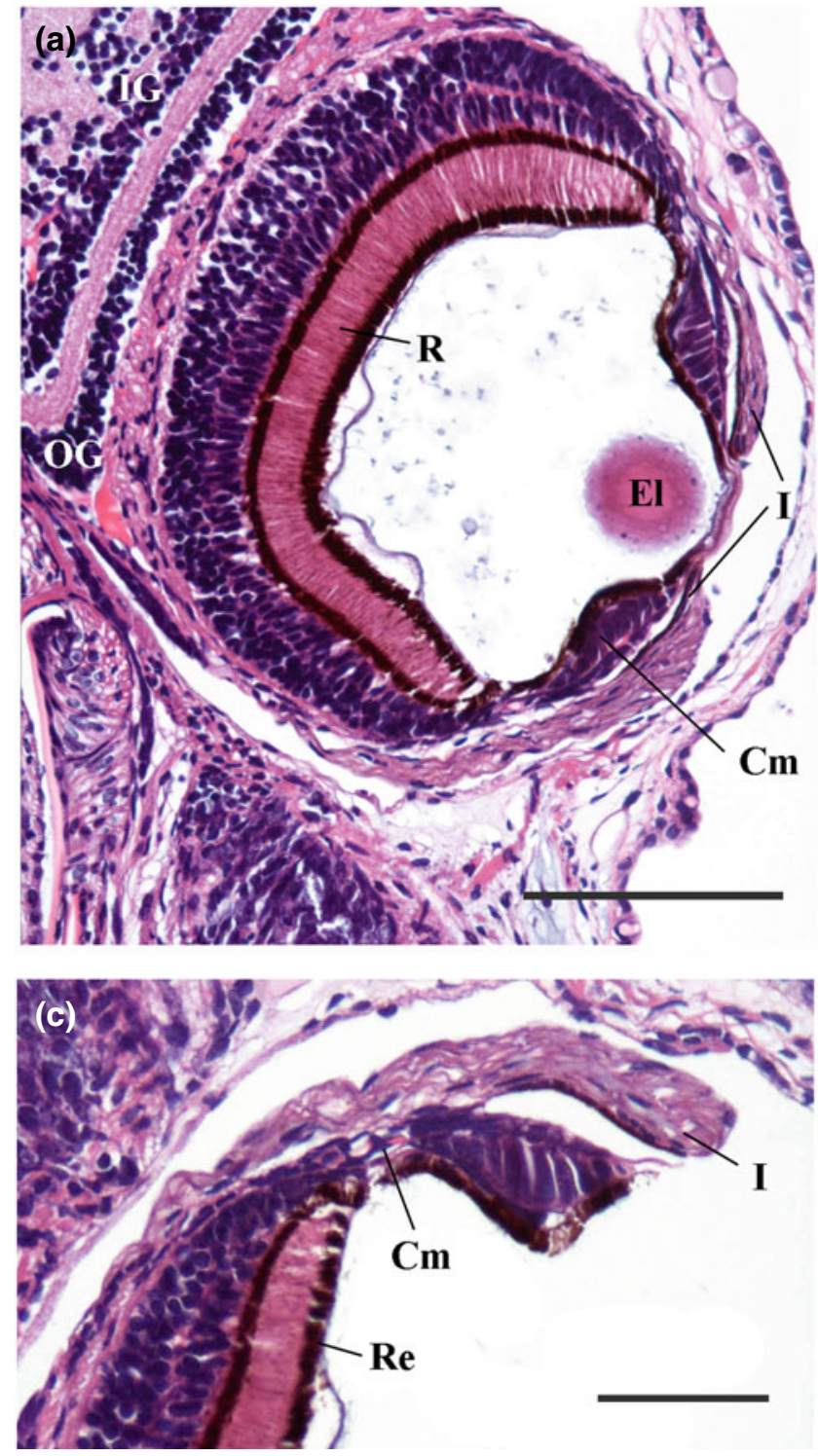

Fig. 5.16 Longitudinal section of the $O$. vulgaris head showing an eye (a). Longitudinal section of the $O$. vulgaris optic nerves and optic lobe (b). Detail of $O$. vulgaris ciliary body and iris (c). Detail of the $O$. vulgaris retina (d). Bs, basal region of distal segments of the visual cell filled with pigment granules; $\mathrm{Cm}$, ciliary body; Ds, distal region of
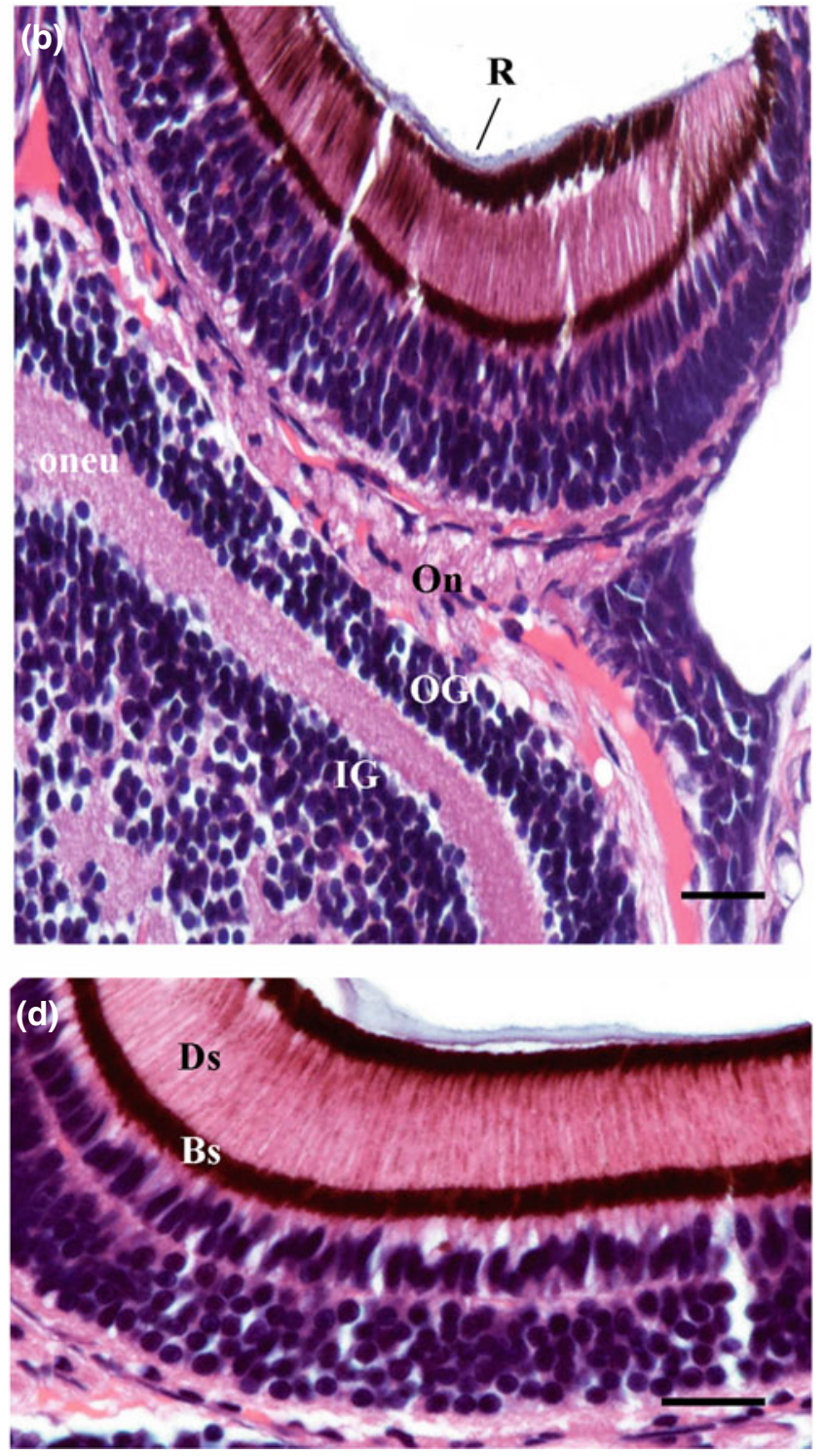

photoreceptor segments bearing rhabdomeres and pigment granules; El, eye lens; I, iris; IG, inner granular cells; OG, outer granular cells; oneu, outer neuropil; and $\mathrm{R}$, retina. a-e H\&E stain. Scale bars: a $100 \mu \mathrm{m}$; b $25 \mu \mathrm{m} ; \mathbf{c} 50 \mu \mathrm{m} ; \mathbf{d} 10 \mu \mathrm{m}$ 
Concerning the suboesophageal mass, the hatchlings show a developed pedal lobe (Fig. 5.14a, b). A brachial lobe entailing short brachiopedal connectives is described in hatchling cuttlefish (Wild et al. 2015). The supra-oesophageal mass is more complex, and it is composed laterally by the basal and peduncular lobes and anteriorly by the vertical and subvertical lobes (Fig. 5.14a, b). Moreover, in the most anterior part posteriorly to the buccal mass, a buccal lobe can also be observed (Fig. 5.14a). The arrangement of these lobes is simpler than those in adults. The vertical lobe, in adults, has a very characteristic shape with five lobules. Most of the lobes in the hatchlings are formed by a central extended neuropil surrounding by densely packed groups of neurons. The size of the neurons varies from small to large (Fig. 5.14e). Group of fibres forming nerves connect these lobes with small ganglia located along the body. In the hatchling cuttlefish and octopus, it is possible to see the neuropil of the stellate ganglia receiving fibres from the pedal lobe through a coarse pallial nerve (Fig. 5.15a, b). Moreover, the muscular organ (bolsters) of the buccal mass receive innervation from the buccal lobe $(5.15 \mathrm{c}, \mathrm{d})$. The connection of the buccal lobe in adults has been described by Young (1971), "the superior buccal lobes send nerves directly to the posterior salivary glands and, via inferior buccal ganglia (which are connected to the superior buccal lobes by interbuccal connectives) to the anterior salivary glands, the muscles of the jaws and the radula".
In addition to the review of Young (1971), more recently Wild et al. (2015) published a specialized monograph on the nervous system of six species of hatchling cephalopod using histology and 3D modelling.

\subsection{Sensory System (Figs. 5.16 and 5.17)}

Cephalopods have numerous sensory organs (Budelmann 1994; Budelmann and Tu 1997) such as large and well-developed eyes, a paired statocyst, a system similar to the fish lateral line, extraocular photoreceptor organs. Some octopuses are also sensitive to chemical and tactile stimuli.

\subsubsection{The Visual System (Fig. 5.16)}

All cephalopods possess eyes although there are differences in their morphology. The eyes are mostly spherical, but sometimes oval, telescopic or stalked (Wentworth and Muntz 1989; Young 1970, 1991). The Coleoidea eyes contain all the major components of a complex vertebrate eyes (Budelmann et al. 1997), namely: cornea (except those of Todarodes, Illex and Ommastrephes), iris, retina, pupil (which can be circular, horizontal or irregular in shape) and rigid lens that are suspended by ciliary muscles which allow for some near vision (Messenger 1981, 1991; Hartline and Lange 1984). (a)

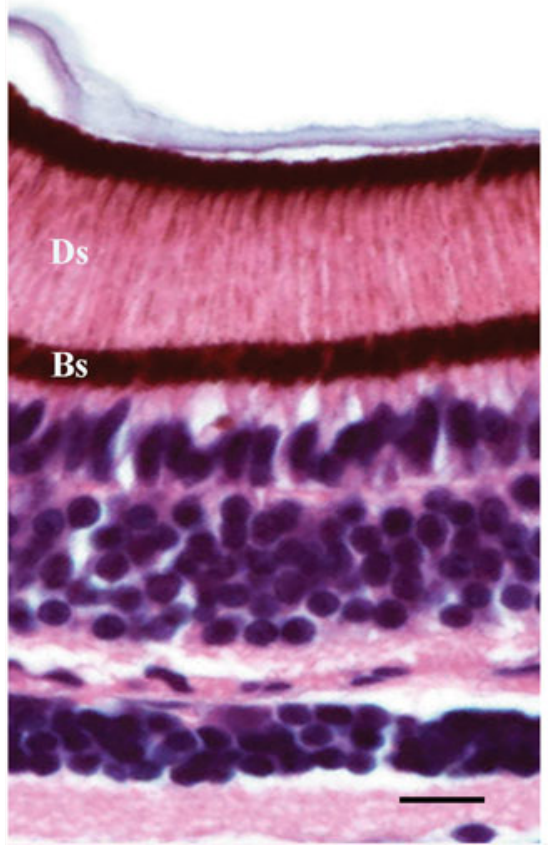

(b)

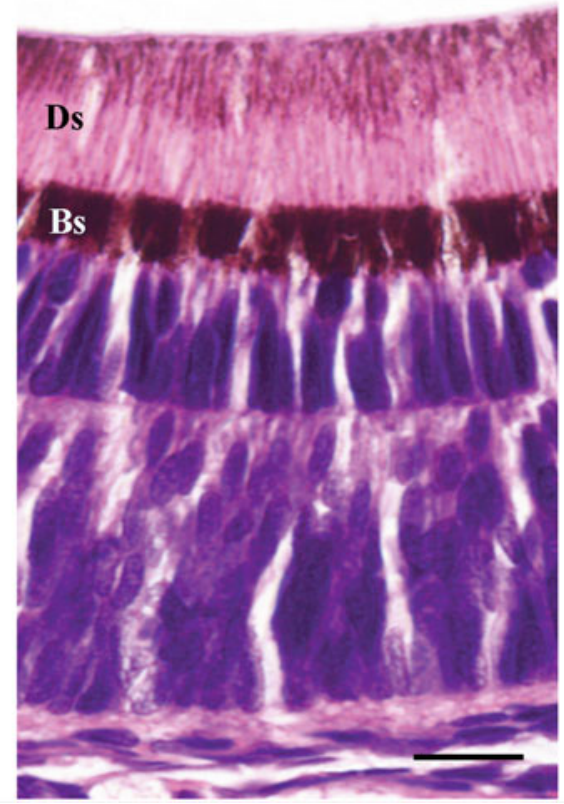

(c)

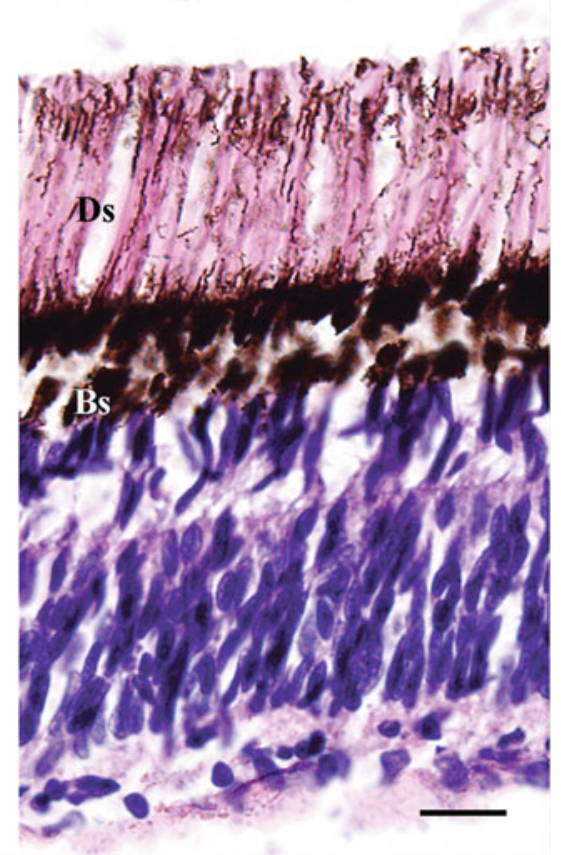

Fig. 5.17 Longitudinal section of the $O$. vulgaris retina (a). Longitudinal section of $L$. vulgaris retina (b). Longitudinal section of the $S$. officinalis retina (c). Bs, basal segment of the visual cell filled with pigment granules and Ds, distal photoreceptive segments bearing the rhabdomeres and pigment granules. a-c H\&E stain. Scale bars: a $10 \mu \mathrm{m}$ and b-c $20 \mu \mathrm{m}$ 

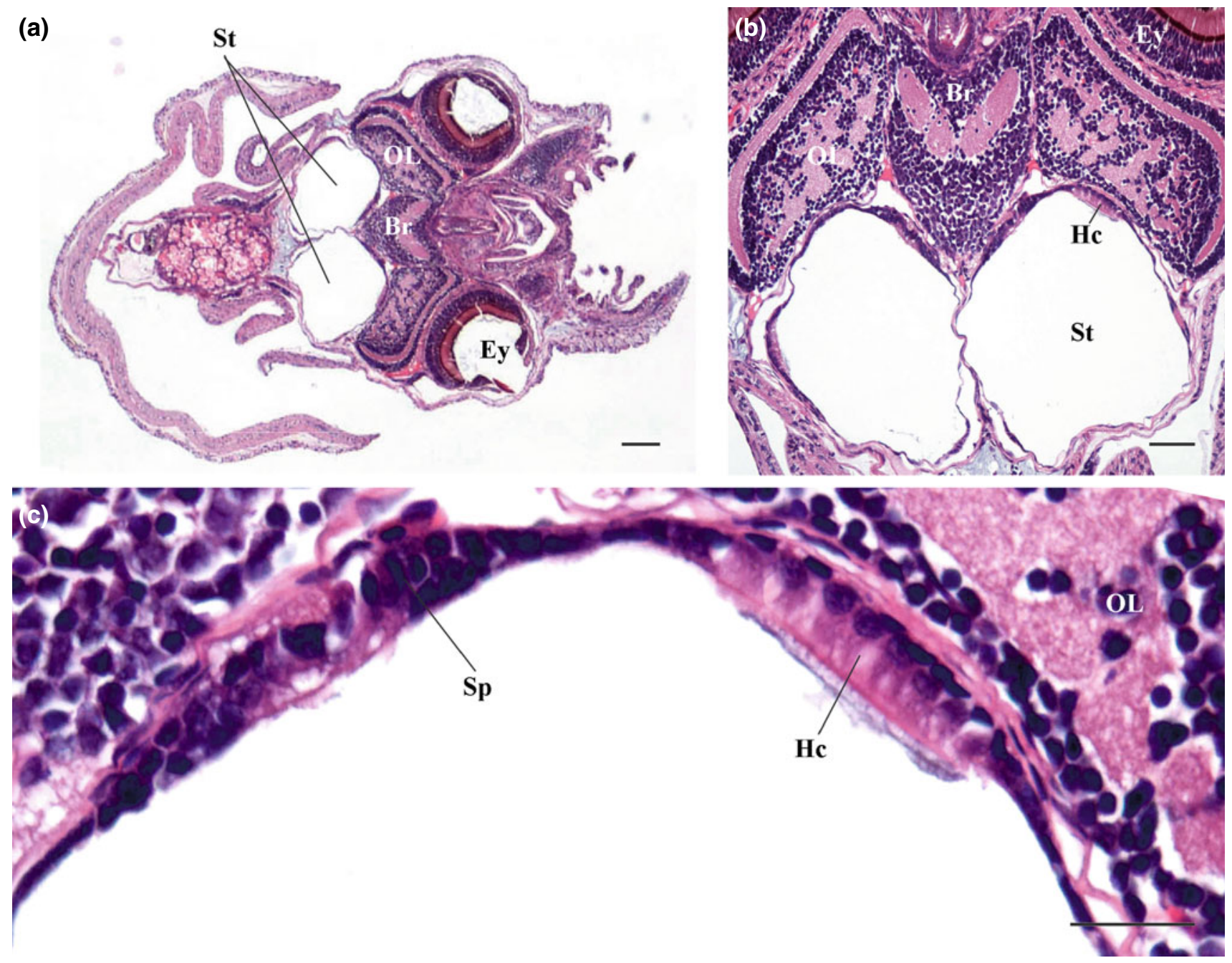

Fig. 5.18 Horizontal section of an O. vulgaris paralarva (a). Close view of statocysts (b). Detail of sensory areas of statocyst. Br, brain; Ey, eyes; Hc, hair cells; OL, optic lobes; Sp, supporting cells; St, statocyst. a-c H\&E stain. Scale bars: a $100 \mu \mathrm{m} ; \mathbf{b} 50 \mu \mathrm{m}$; and $\mathbf{c} 25 \mu \mathrm{m}$

The cephalopod iris is formed of five layers: external epithelium, chromatophore layer, iridophore layer, muscle and collagen fibre layer and pigment epithelium (Froesch 1973). The cephalopod retina is less developed than those in vertebrates. It is formed by receptor cells (primary sensory cells) and efferent fibres. The visual information from the retina runs to large optic lobes through the optic nerve (Budelmann 1994). The behaviour response of embryos to visual stimulus and their ability to learn visual features of potential prey indicate that the visual system, including the optic lobes, is functional before hatching (Darmaillacq et al. 2014).

In the hatchling octopus, squid and cuttlefish, the eyes are completely developed and have the same structure than in adults (Fig. 5.16). In some structures such as the retina, differences in the thickness or development of some of its layers are observed (Fig. 5.17). The plexiform layer is more developed in the first few days post-hatching. In Loligo, the pigmentary granules in the apical rhabdomere region are scarce (Fig. 5.17b).

\subsubsection{The Statocysts (Fig. 5.18)}

These structures are situated in the cranial cartilage and show a variety of forms in cephalopods (Budelmann et al. 1997). In octopus, this is a spherical sac (Fig. 5.18a, b) with a balance system and an angular acceleration system divided into nine segments (Young 1960). However, in decapods, this structure is irregularly shaped and has three gravity 
receptor systems and an angular acceleration system (Stephens and Young 1982). The equilibrium receptor organs provide information regarding body position. Different animals have different requirements for this organ depending on lifestyles and habitats. In general, fast-moving species orient themselves with respect to the direction of gravity (and other linear accelerations), as well as respond to rotatory body movements (angular accelerations) (Neumeister and Budelmann 1997). Consequently, the equilibrium receptor organs include two different receptor systems: a gravity receptor system for the detection of position relative to the direction of gravity and an angular acceleration receptor system for the detection of rotatory movements (Neumeister and Budelmann 1997).

Both receptor systems are formed by two types of cells, hair cells which are voluminous and have a large nucleus and microvillous supporting cells (Fig. 5.18c). The gravity receptor system comprises the macula epithelium and the accessory statolith. The hair cells of the macula are in different arrangements: concentric and half circles or in $360^{\circ}$ or $180^{\circ}$ radial fan-like. The other receptor system, an angular acceleration system, is formed by the crista epithelium with the cupula. This structure forms ridges that run inside the statocyst in the three dimensions of space.

The crista segments are composed of primary sensory hair cells and two types of secondary hair cells (Budelmann 1994). Along each crista segment, the hair cells are arranged in two or four regular rows. Just like in the macula, between the hair cells, there are supporting cells.

\subsection{Concluding Remarks}

The histological anatomy study of premature hatchlings of squid (L. vulgaris) and cuttlefish (S. officinalis) and of paralarvae of octopus (O. vulgaris) shows that most systems and their characteristic structures are present. However, comparing these structures with the adults of the same species it is possible to conclude that in general the level of development is lower. This lack of development is easily observed in digestive and circulatory systems. In the digestive system, the absence of glandular epithelia associated with the posterior part of the lateral lobes and the jaw during these stages of development is characteristic. It is also remarkable the low number of secretory cells in regions such as the caecum and intestine, where mucous secretions help the excretion of waste products resulting from digestion. Moreover, the octopus and squid intestines are the most underdeveloped organ in the digestive system. There are no folds or villi, the epithelium is simple squamous, and no secretory cells are present in the most part of the tube. In the circulatory system, a low level of development has been found in the branchial hearts and also in the systemic heart. In hatchling cephalopods, the branchial hearts present a large lumen that is absent in adults. Likewise, systemic a poorly developed wall is observed in the systemic heart of all the studied species. In paralarvae and juvenile, the systemic heart does not have the strong musculature observed in the systemic heart of adults.

In some instances, the degree of development in hatchling cephalopods is similar to that in adults. This happens, for example, in defensive systems, the ink complex, the structures that help in the prey capture and the visual system. In hatchling octopus, squid and cuttlefish, the eyes are completely developed. Only in the retina, differences in the thickness or development of some of its layers are observed.

Finally, there are tissues that change throughout the development to adapt to different habitats. This occurs in structures such as the L. vulgaris and $S$. officinalis epidermis where a large number of globet cells are observed differ from the characteristic epithelium of adults. Another example is the characteristic Kölliker cells that appear only in the epidermis of octopus paralarvae, disappearing after the first month of post-embryonic life.

The study of all tissues and systems in premature hatchling of squid (L. vulgaris) and cuttlefish (S. officinalis) and of paralarvae of octopus (O. vulgaris) allows us to conclude that although most systems are present, the majority of them show a lower degree of development than in adults. Some systems, mainly those related to sensory systems, present a similar development, and others change their morphological characteristics.

Acknowledgements We would like to thank Antonio Sykes (CCMAR-CIMAR) who generously donated the paraffin blocks from which the sections of $S$. officinalis were prepared.

\section{References}

Bidder AM (1950) The digestive mechanism of the European squids Loligo vulgaris, Loligo forbesi, Alloteuthis media and Alloteuthis subulata. Q J Microsc Sci 91:1-43

Bizikov VA (1987) New data on squid gladius structure. Zool Zhur 46 (2):177-184

Boletzky SV (1973) Structure and function of the Kölliker organs in young octopods (Mollusca, Cephalopoda). Z Morphol Tiere 75:315-327

Boletzky SV (1983) Sepia officinalis. In: Boyle PR (ed) Cephalopod life cycles, vol 2 Species accounts. Academic Press, San Diego, pp 31-52

Boletzky SV, Wiedmann J (1978) Schlup-Wachstum bei Sepia officinalis in Abhängigkeit von ökologischen Parametern. Neues Jahrb Geol P-A 157:103-106 
Boucher-Rodoni R, Mangold K (1988) Comparative aspect of ammonia excretion in cephalopods. Malacology 29:145-151

Brocco SL, O'Clair R, Cloney RA (1974) Cephalopod integument: the ultrastructure of Kölliker's organs and their relationship to setae. Cell Tissue Res 151:293-308

Budelmann BU (1994) Cephalopod sense organs, nerves and the brain: adaptations for high performance and life style. Mar Freh Behav Physol 25:13-33

Budelmann BU, Tu Y (1997) The statocyst-oculomotor reflex of cephalopods and the vestibulo oculomotor reflex of vertebrates: a tabular comparison. Vie Milieu 47:95-99

Budelmann BU, Schipp R, Boletzky Sv (1997) Cephalopoda. In: Harrison FW, Kohn AJ (eds) Microscopic anatomy of invertebrates, Mollusca ii, vol 6a. Wiley-Liss, New York, pp 235-271

Derby DD (2014) Cephalopod ink: production, chemistry, functions and applications. Mar Drugs 12:2700-2730.

Dilly PN, Messenger JB (1972) The branchial gland: a site of haemocyanin synthesis in octopus. Z Zellforsch Mik An 2:192-221

Fernández-Gago R, Heb M, Gensler H. Rocha F (2017) 3D reconstruction of the digestive system in Octopus vulgaris Cuvier, 1797 embryos and paralarvae during the first month of life. Front Physiol 04 July 2017. https://doi.org/10.3389/fphys.2017.00462

Fiedler A, Schipp R (1987) the role of the branchial heart complex in circulation of coleoid cephalopods. Experientia 43(5):544-553

Fioroni P (1990) Our recent knowledge of the development of the cuttlefish (Sepia officinalis). Zool Anz 224:1-25

Froesch D (1973) On fine structure of the octopus iris. Z Zellforsch Mikrosk Anat 145:119-129

Frösch D (1971) Quantitative Untersuchungen am Zentralnervensystem der schlüpfstadien von zhen mediterranen Cephalopodenarte. Rev Suisse Zool 78:1069-1122

Furuya H, Ota M, Kimura R, Tsuneki K (2004) Renal organs of cephalopods: a habitat for dicyemids and chromidinids. J Morph 262:629-643

Hanlon RT, Messenger JB (1988) Adaptive coloration in young cuttlefish (Sepia offcinalis L.): the morphology and development of body patterns and their relation to behaviour. Phil Trans Roy Soc B Biol Sci 320:437-448

Hartline PH, Lange GD (1984) Visual systems of cephalopods. In: In Bolis L, Keynes RD, Maddrell SHP (eds) comparative physiology of sensory systems. Cambridge University Press, Cambridge, pp 335-355

Hopkins B, Boletzky Sv (1994) The fine morphology of the shell sac in the squid genus Loligo (Mollusca: Cephalopoda) features of a modified conchiferan program. Veliger 37:344-357

Iglesias J, Sánchez FJ, Bersano JGF, Carrasco JF, Dhont J, Fuentes L, Linares F, Muñoz JL, Okumura S, Roo J, van der Meeren T, Vidal EAG, Villanueva R (2007) Rearing of Octopus vulgaris paralarvae: present status, bottlenecks and trends. Aquaculture 266:1-15

Johnson FE (1987) The vasculature of the white bodies in the ommastrephid squid Illex illecebrosus (Lesueur, 1821): a proposed route for dissemination of newly formed haemocytes. Can J Zool 65:1607-1620

Kling G, Schipp R (1987) Comparative ultrastructural and cytochemical analysis of the cephalopod systematic heart and its innervation. Experientia 43(5):502-511

Laurie M (1888) The organ of Verril in Loligo. J Cell Sci s2-29: 97-100

Lemaire J, Richard A, Decleir W (1977) Le foie embryonnaire de Sepia officinalis L. (Mollusque Cephalopode). I. Organogenèse. Haliotis 6:287-296

Mangold K, Sv Boletzky, Frösch D (1971) Reproductive biology and embryonic development of Eledone cirrosa (Cephalopoda, Octopoda). Mar Biol 8:109-117
Mangold K, Bidder AM, Portmann A (1989) Structures cutaneés: la poche du noir. In: Grassé PP (ed) Céphalopodes. Traité de Zoologie 5/4. Masson, Paris, France, pp 154-162

Messenger JB (1973) Learning performance and brain structure: a study in development. Brain Res 58:519-528

Messenger JB (1981) Comparative physiology of vision in molluscs. In: Autrum $\mathrm{H}$ (ed) Comparative physiology and evolution of vision in invertebrates. Handbook of Sensory Physiology, vol vii/6c. Springer Verlag, Berlin, pp 93-200

Messenger JB (1991) Photoreception and vision in molluscs. In: Cronly-Dillon JR, Gregory RL (eds) Evolution of the eye and the visual system. McMillan, London, pp 364-397

Naef A (1923) Die Cephalopoden. Monographie 35, volume i, parts i and ii, Sistematik. Fauna und Flora der Golfo di Napoli

Neumeister H, Budelmann BU (1997) Structure and function of the nautilus statocyst. Phil Tran Roy Soc B Biol Sci 352:1565-1588

Nixon M, Mangold K (1996) The early life of Octopus vulgaris (Cephalopoda, Octopodidae) in the plankton and at settlement: a change in life style. J Zool 239:301-327

Portmann A (1933) Observations sur la vie embryonnaire de la pieuvre (Octopus vulgaris Lam.). Arch Zool Exp Gen 76:24-36

Schipp R (1987) General morphological and functional characteristics of the cephalopod circulatory system. An introduction. Experientia 43(5):474-477

Schipp R, Schäfer A (1969) Vergleichende elektronenmikroskopische untersuchungen an den zentralen herzorganen von cephalopoden (Sepia officinalis). Z Zellforsch Mikrosk Anat 101:367-379

Schipp R, Mollenhauer S, Sv Boletzky (1979) Electron microscopical and histochemical studies of differentiation and function of the cephalopod gill (Sepia officinalis). Zoomorphologie 93:193-207

Shigeno S, Tsuchiya K, Segawa S (2001) Embryonic and paralarval development of the central nervous system of the loliginid squid Sepioteuthis lessoniana. J Comp Neurol 437:449-475

Stephens PR, Young JZ (1982) The statocyst of the squid Loligo. J Zool 197:241-266

Sundermann G (1983) The fine structure of epidermal lines on arms and head of postembryonic Sepia officinalis and Loligo vulgaris (Mollusca, Cephalopoda). Cell Tissue Res 232: 669-677

Thompsett DH (1939) Sepia. Liverpool marine biological committee. Memoirs on typical British marine plants \& animals, Universal Press of Liverpool 32, p 184

Villanueva R (1995) Experimental rearing and growth of planktonic Octopus vulgaris from hatching to settlement. Can J Fish Aqua Sci 52:2639-2650

Voss GL (1963) Function and comparative morphology of the funnel organ in cephalopods. In: Proceedings of the XVI International Congress of Zoology, Washington, DC, USA, 20-27 August 1963, vol $1, \mathrm{p} 74$

Wells MJ, Wells J (1982) Ventilatory currents in the mantle of cephalopods. J Exp Biol 99:315-330

Wentworth SL, Muntz WRA (1989) Asymmetries in the sense organs and central nervous system of the squid Histioteuthis. J Zool 219:607-619

Wild E, Wollesen T, Haszprunar G, Heb M (2015) Comparative 3d microanatomy and histology of the eyes and central nervous systems in coleoid cephalopod hatchlings. Org Divers Evol 15:37-64

Yamazaki A, Yoshida M, Uematsu K (2002) Post-hatching development of the brain in Octopus ocellatus. Zool Sci 19:763-771

Yun DK, No HK, Prinyawiwatkul W (2013) Preparation and characteristics of squid pen $\beta$-chitin prepared under optimal deproteinisation and demineralisation condition. Int $\mathrm{J}$ Food Sci Tech 48:571-577

Young JZ (1960) The statocyst of Octopus vulgaris. Proc Roy Soc B Biol Sci 152:3-29 
Young JZ (1970) The stalked eyes of Bathothauma (Mollusca: Cephalopoda). J Zool 162:437-447

Young JZ (1971) The anatomy of the nervous system of Octopus vulgaris. Clarendon Press, Oxford

Young JZ (1977) Brain, behaviour and evolution of cephalopods. Symp Zool Soc London 38:377-434
Young JZ (1979) The nervous system of Loligo, V: the vertical lobe complex. Phil Trans Roy Soc B Biol Sci 285:311-354

Young JZ (1991) Light has many meanings for cephalopods. Visual Neurosci 7(1-1):2

Young RE, Harman RF (1988) "Larva", "paralarva" and "subadult" in cephalopod terminology. Malacologia 29:201-207
Open Access This chapter is licensed under the terms of the Creative Commons Attribution 4.0 International License (http:// creativecommons.org/licenses/by/4.0/), which permits use, sharing, adaptation, distribution and reproduction in any medium or format, as long as you give appropriate credit to the original author(s) and the source, provide a link to the Creative Commons licence and indicate if changes were made.
The images or other third party material in this chapter are included in the chapter's Creative Commons licence, unless indicated otherwise in a credit line to the material. If material is not included in the chapter's Creative Commons licence and your intended use is not permitted by statutory regulation or exceeds the permitted use, you will need to obtain permission directly from the copyright holder. 